\title{
Evaluación del retroceso glaciar de la Sierra Nevada del Cocuy, Colombia a partir de la clasificación de imágenes multisensor
}

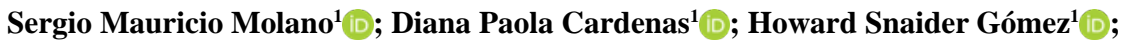 \\ Dayana Mairely Alvarado ${ }^{1}$; Andrés Fernando Galindo ${ }^{2} \mathbb{D}$; Jeisson Fabian Sanabria ${ }^{2} \mathbb{D}$; \\ Juan Sebastian Gómez-Neita ${ }^{1,2,3^{*}}$ (D)
}

Forma de citar: Molano, S.M.; Cardenas, D.P.; Gómez, H.S.; Alvarado, D.M.; Galindo, A.F.; Sanabria, J.F.; Gómez-Neita, J.S. (2022). Evaluación del retroceso glaciar de la Sierra Nevada del Cocuy, Colombia a partir de la clasificación de imágenes multisensor. Boletín de Geología, 44(1), 49-73. https://doi.org/10.18273/revbol. v44n1-2022002

\begin{abstract}
Resumen
Los glaciares andinos representan una de las fuentes principales del recurso hídrico en Suramérica y durante las últimas décadas se han reducido significativamente como producto del cambio climático y la variabilidad climática. En los Andes colombianos, el pico nevado más extenso corresponde a la Sierra Nevada del Cocuy (SRC), un cordón montañoso localizado al noreste de la Cordillera Oriental con presencia de nieves perpetuas en alturas que oscilan aproximadamente entre los 4800 y los 5345 metros sobre el nivel del mar (msnm). A partir de imágenes satelitales de Landsat-4 (1987), Landsat-5 (1991, 1997, 2009), Landsat-7 (2000, 2003), Landsat-8 (2014, 2016, 2017), y Sentinel-2 $(2019,2021)$ se realizó una clasificación orientada a píxel usando el software PCI Geomatics, en la cual se definieron 4 tipos de cobertura: área glaciar, suelo-roca, vegetación y agua. Para la validación de exactitud (accuracy) fueron utilizadas como datos de referencia, imágenes satelitales de alta resolución espacial (Google Earth 1,0 m y Planet's high-resolution, analysis-ready mosaics of the world's tropics $\sim 4,7 \mathrm{~m}$ ) y puntos de control de campo. Los valores de exactitud global (todas las coberturas) oscilaron entre 86-99\%, con una exactitud para la cobertura de área glaciar entre $97-100 \%$. La disminución de dicha área es de 1099,59 ha en un lapso de 34 años (1987-2021). Este análisis reveló que el área glaciar disminuyó aproximadamente en un 37,92\% con respecto a la primera escena (1987). Según dicha tendencia, el glaciar de la SRC se extinguiría para el año 2048. La tasa de retroceso glaciar está influenciada principalmente por factores relacionados con el calentamiento global como lo son el aumento de la temperatura media anual y la disminución en las tasas de precipitación, y factores de variabilidad climática como el fenómeno de El Niño.
\end{abstract}

Palabras clave: Andes; Cambio climático; Variabilidad climática; Exactitud; Clasificación supervisada.

\section{Assessment of glacier retreat in the Sierra Nevada del Cocuy, Colombia based on multisensor image classification}

\begin{abstract}
The Andean glaciers represent one of the most important water sources in South America. They have been significantly reduced in recent decades because of climate change and climate variability. The most extensive snow-capped peak in the Colombian Andes Mountains corresponds to the Sierra Nevada del Cocuy (SRC), a mountain range located toward the northeast of the Eastern Cordillera with snow at altitudes ranging from approximately 4800 to 5345 meters above sea level (masl). From Landsat-4 (1987), Landsat-5 (1991, 1997, 2009), Landsat-7 (2000, 2003), Landsat-8 (2014, 2016, 2017), and Sentinel-2 (2019, 2021) satellite imagery, a pixel-oriented classification was performed using the PCI Geomatics software, defining four cover types: glacier area, soil-rock, vegetation, and water. For accuracy validation, high spatial resolution satellite imagery (Google Earth $\sim 1.0 \mathrm{~m}$ and Planet's high-resolution, analysis-ready mosaics of the world's tropics $\sim 4.7 \mathrm{~m}$ ) and field control points were used as reference data. Overall accuracy values (all coverages) ranged from $86-99 \%$, with accuracy for glacier area coverage between $97-100 \%$. The decrease in the glacier area is of 1099.59 ha over 34 years (1987-2021). This analysis revealed that the glacier area decreased by approximately $37.92 \%$ regarding the first scene (1987). According to this trend, the SRC glacier would be extinct by 2048 . The rate of glacier retreat is mainly influenced by factors related to global warming, such as the increase in mean annual temperature and the decrease in precipitation rates and climate variability factors such as the El Niño phenomenon.
\end{abstract}

Keywords: Andes; Climate change; Climate variability; Accuracy; Supervised classification.

${ }^{1}$ Programa de Pós-graduação em Geologia e Geoquímica, Instituto de Geociências, Universidade Federal do Pará, Belém, Brasil.sergio.cardenas@ig.ufpa.br; diana.ruiz@ig.ufpa.br; howard.cepeda@ig.ufpa.br; dayana.sierra@ig.ufpa.br

${ }^{2}$ Grupo de Investigación en Ingeniería Geológica, Escuela de Ingeniería Geológica, Universidad Pedagógica y Tecnológica de Colombia, Sogamoso, Colombia. andres.galindo@uptc.edu.co; jeissonsanabria48@gmail.com

${ }^{3}$ Programa de Pós-graduação em Geociências, Instituto de Geociências, Universidade Federal do Rio Grande do Sul, Porto Alegre, Brasil. (*) juan.gomezneita@uptc.edu.co. 


\section{Introducción}

Los glaciares son cuerpos de hielo con un comportamiento dinámico. Estos se originan en el continente como resultado de la precipitación de formas sólidas o recristalización de nieve, incorporando detritos durante su desplazamiento (Knight, 1999; IDEAM, 2012; Quintero, 2018). Los glaciares de montaña, como los que se encuentran en los Andes colombianos están presentando un proceso de retroceso (Bautista y Correa, 2018; Quintero, 2018), por lo cual documentar sus cambios a largo plazo es importante para los estudios de cambio climático y disponibilidad de agua (Metsämäki et al., 2015). El impacto del cambio climático en los glaciares andinos se encuentra entre los más severos a nivel mundial, comparable al de las latitudes altas del hemisferio norte, particularmente en términos de aumento de temperatura a mayores altitudes (Anderson et al., 2011). En estos glaciares, la zona de equilibrio puede variar y en consecuencia generar mayor ablación; afectando directamente el abastecimiento de las cuencas hidrográficas que alimentan los glaciares (Kaser y Georges, 1999; Herrera y Ruiz, 2008; Mark, 2008; Quintero, 2018). Los glaciares tropicales están influenciados por el doble paso de la Zona de Convergencia Intertropical (ZCIT), la cual controla la dinámica de precipitaciones y temperatura en estas áreas (Rekowsky et al., 2018).

Conforme a la altura en la que ocurren, los glaciares tropicales presentan ciertas condiciones favorables para la precipitación de nieve y formación de hielo (HoyosPatiño, 1998; Knight, 1999; Rekowsky et al., 2018; Quintero, 2018; Veettil y Kamp, 2019). Actualmente, en Colombia existen 6 glaciares activos, 1 en la Cordillera Oriental, 4 en la Cordillera Central y 1 en el norte del país en cercanías a la costa Caribe (Rekowsky et al., 2018; Quintero, 2018). En la Cordillera Oriental el único cuerpo glaciar es la Sierra Nevada del Cocuy (IDEAM, 2019), esta se presenta como una franja alargada en dirección S-N compuesta por rocas sedimentarias y abundantes depósitos Cuaternarios, predominantemente de origen glaciar (Fabre, 1981). Los glaciares que se presentan en el norte andino son limitados en extensión, espesor y volumen en comparación con los glaciares localizados en altas latitudes. El espesor de hielo presente en la SRC alcanza hasta $30 \mathrm{~m}$ en las secciones más altas y $\sim 4 \mathrm{~m}$ hacia los bordes (Ancizar, 1955). Su limitada extensión y espesor, así como las variaciones en el clima los hacen vulnerables al efecto de ciertos factores climatológicos, principalmente precipitación y temperatura.
La SRC se encuentra formada por 37 masas de hielo localizadas principalmente en la vertiente occidental donde existen pendientes menos pronunciadas (Herrera y Ruiz, 2008; IDEAM, 2019). Estas masas se encuentran relativamente conservadas debido a la humedad proveniente del oriente y su presencia en altitudes superiores a los 4800 msnm (IDEAM, 2019). A pesar de esto, existen factores que favorecen el retroceso glaciar en la SRC como lo es el aumento en el flujo de radiación solar provocado por la disminución del albedo, lo que conlleva a un aumento progresivo de la temperatura media anual (Rabatel et al., 2013). Esto exhibe la incidencia del cambio climático y representa una problemática referente a la disponibilidad del recurso hídrico, posibles avalanchas y microclimas en las altas montañas de la Cordillera Oriental (Feo et al., 2009; García et al., 2012; Rapp, 2014).

Los sensores remotos representan una herramienta poderosa que ofrece la capacidad de examinar cuantitativamente la cobertura glaciar en áreas distantes o de acceso restringido, donde las mediciones in situ representan un desafío logístico y financiero (König et al., 2001; Nolin, 2010). La aplicabilidad de estas técnicas suele estar relacionada con el empleo de umbrales de índices de diferencia normalizada, especializados en el monitoreo de nieve como: "Normalized Difference Snow/ Ice Index" (NDSII) (Xiao et al., 2001), "Normalized Difference Forest Snow Index" (NDFSI) (Wang et al., 2015), y el "Normalized Difference Snow Index" (NDSI), el cual es ampliamente usado para el monitoreo de grandes coberturas de nieve (Dozier, 1989), sin embargo, el uso de este umbral de índices diferenciados como NDSI puede generar grandes incertidumbres para la estimación de nieve, al menos a escala local (Härer et al., 2018), como es el caso de los glaciares andinos. Por lo tanto, datos adicionales como toda la información espectral disponible de los sensores y corroboración in situ, son necesarios para una evaluación íntegra de la cobertura glaciar.

Este trabajo pretende definir la variación en la cobertura glaciar de la SRC durante las últimas cuatro décadas utilizando productos de sensores remotos, dicha variación indica un retroceso glaciar que ya ha sido documentado previamente por otros autores (e.g., Florez, 1991; Guillen et al., 2004; Ceballos et al., 2006; Morris et al., 2006; Herrera y Ruiz, 2008; Bautista y Correa, 2018; Rekowsky et al., 2018; Quintero, 2018). No obstante, este estudio ofrece datos imprescindibles sobre la validación de los resultados (exactitud) usando 
productos ópticos de mayor resolución espacial y trabajo de campo. Dichos resultados serán de gran importancia pues permitirá establecer la dinámica glaciar de la SRC y su relación con respecto a los efectos del cambio climático y variabilidad climática de finales del siglo XX y comienzos del siglo XXI en el norte de Suramérica.

\section{Conjunto de datos y métodos}

\section{Área de estudio y parámetros climáticos}

El área de estudio se localiza al este de los Andes colombianos entre los departamentos de Boyacá y
Arauca con una extensión de $\sim 7565$ ha (Figura 1). Geológicamente, la SRC se encuentra ubicada en la Cuenca Cordillera Oriental, la cual esta divida por el alto de Santander en dos subcuencas principales, Tablazo Magdalena al occidente y Cocuy al este (Etayo et al., 1969; Cooper et al., 1995). La SRC localizada en la Subcuenca del Cocuy alcanza altitudes de hasta 5345 msnm y según Rekowsky et al. (2018) es el glaciar más extenso de Colombia. Las condiciones topográficas de la SRC permitieron una mayor acumulación de hielo principalmente en la vertiente occidental (IDEAM, 2001; Herrera y Ruiz, 2008; Rekowsky et al., 2018).
Sentinel-2 MSI: 2019-02-25

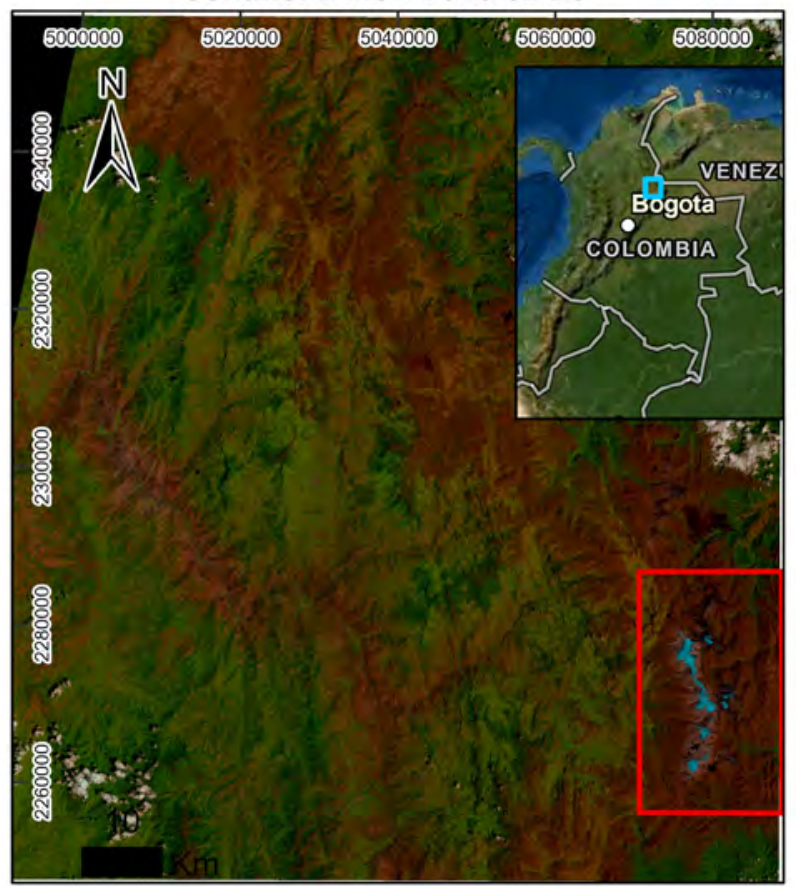

Landsat 8 OLI: 2017-12-20

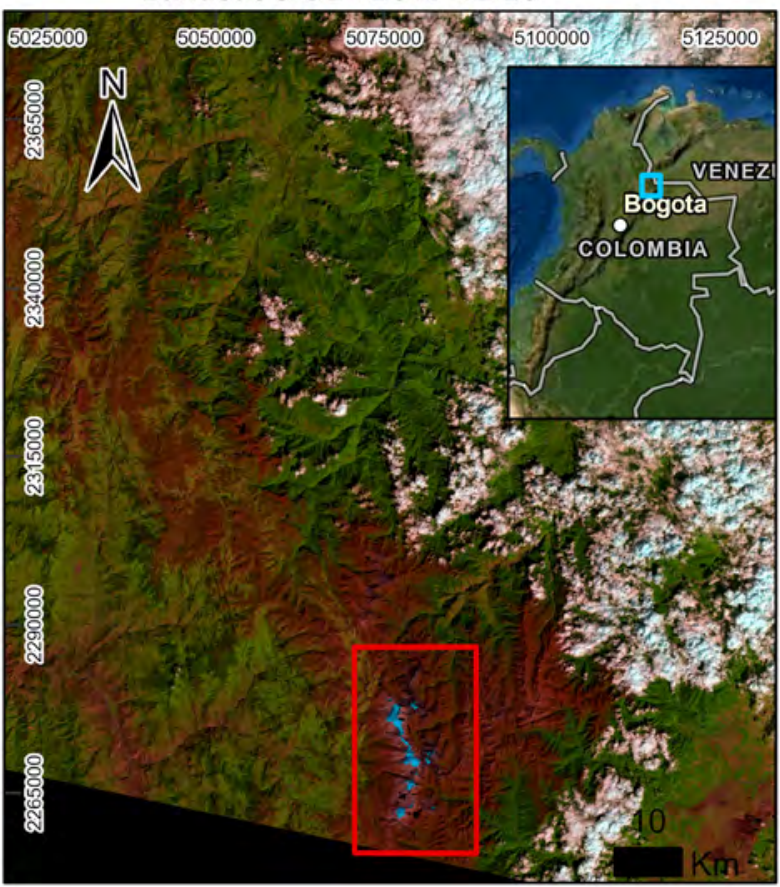

Referencia espacial: MAGNA-SIRGAS CTM12, Proyección Transversa de Mercator, DATUM MAGNA SIRGAS, Origen geográfico: -73,0, 4,0, Factor de escala: 0,9992, EPSG: 9377, Unidades: metros.

Área de estudio

Área de adquisición de imágenes satelitales Landsat 8 y Sentinel 2

Figura 1. Localización del área de estudio en imágenes satelitales adquiridas de Sentinel-2 (cuadrícula mundial en gránulos o tiles de $100 \times 100 \mathrm{~km}^{2}$ por unidad) y Landsat- 8 (cuadrícula mundial de referencia WRS-2).

En esta región, predominan paisajes montañosos con vastas áreas de roca expuesta dominantemente de edad cretácica, las cuales corresponden con depósitos marinos y transicionales formando un espeso cordón sedimentario de aproximadamente $7500 \mathrm{~m}$, sobre los cuales descansan abundantes depósitos cuaternarios de tipo aluvial y glaciar (Figura 2) (Cooper et al., 1995).

Esta zona se caracteriza por presentar un régimen de precipitación monomodal en la vertiente oriental y un régimen bimodal en la vertiente occidental (Rodríguez, 2015). Dicho fenómeno es el resultado del doble movimiento de la ZCIT, conocida por ser una región de baja presión, la cual controla la dinámica de los vientos alisios provenientes del noreste y sureste sobre el océano y sobre las masas de tierra en áreas cercanas al Ecuador, generando mayor nubosidad y precipitación (Waliser y Jiang, 2015; Yan, 2015). Este es el caso de la SRC en los Andes colombianos (Rodríguez, 2015; Rekowsky et al., 2018). 
Los valores de precipitación para la estación de la Sierra Nevada del Cocuy reportados por el Instituto de Hidrología, Meteorología y Estudios Ambientales de Colombia (IDEAM) indican un régimen bimodal y valores medios mensuales de precipitación máxima en 24 horas, entre $25 \mathrm{~mm}$ y $65 \mathrm{~mm}$ (Figura 3A). El análisis de este parámetro permite determinar los meses con condiciones apropiadas para la obtención de las imágenes, además de que posibilita tener un conocimiento base de la relación entre la precipitación y la cobertura de nieve. De acuerdo con Gutzler y Preston (1997) cuando la extensión espacial y la duración de la capa de nieve invernal son altas, la cantidad de precipitación en verano es menor y viceversa. Los valores registrados de temperatura media máxima en 24 horas oscilan entre 11,42 y $13,51^{\circ} \mathrm{C}$ para los diferentes meses del año (Figura 3B). Las variaciones de precipitación y temperatura dependen en gran medida de la época del año, localización y altura (Rodríguez, 2015), presentando una relación inversa. Además, dichos valores pueden exhibir fluctuaciones dependiendo de las estaciones meteorológicas analizadas en consecuencia de la dinámica climática local.

Debido al cambio climático, durante las últimas 4 décadas se ha observado una disminución de las masas glaciares en los Andes colombianos (Guillen et al., 2004; Ceballos et al., 2006; Morris et al., 2006; Herrera y Ruiz, 2008; Bautista y Correa, 2018; Rekowsky et al., 2018; Quintero, 2018), lo cual resulta de vital importancia, ya que en estos glaciares nacen numerosas fuentes hídricas. La SRC presenta una divisoria de aguas en dirección S-N con dos vertientes principales, la occidental hacia el río Magdalena y la oriental hacia el río Orinoco (IDEAM, 2019).

La disposición topográfica de la SRC, así como los factores climáticos generan un aporte constante del recurso hídrico principalmente a la vertiente occidental hacia los ríos Lagunillas, Cóncavo, Corralitos, San Pablín y Cardenalillo, los cuales fluyen en dirección al río Nevado que posteriormente desemboca en el río Chicamocha (IDEAM, 2019). En la vertiente oriental nace el río Mortiñal y las quebradas Patio Bolos y las Tapias que desembocan en el río Casanare y los ríos Ratoncito y Cubogón los cuales fluyen hacia el río Arauca (IDEAM, 2019). Las aguas producto de la fusión glaciar de las cuales se benefician algunos pobladores rurales de las zonas más altas, tributan hacia los páramos y estos a su vez contribuyen a la provisión de agua de los principales municipios de la región (e.g., Güicán, Cocuy, Panqueba, etc.) (IDEAM, 2019).

\section{Conjunto de datos de sensores remotos}

Fueron clasificadas 11 imágenes ópticas las cuales se tomaron preferencialmente en la época seca de la SRC para evitar la ocurrencia de nubes. Una escena del sensor TM del satélite Landsat-4 para el año de 1987, 3 escenas de los sensores TM y MSS del satélite Landsat-5 para los años de 1991, 1997 y 2009, 2 escenas del sensor ETM+ del satélite Landsat-7 para los años de 2000 y 2003, 3 escenas de los sensores OLI+TIRS del satélite Landsat- 8 para los años de 2014, 2016 y 2017, y 2 escenas del sensor MSI del satélite Sentinel-2 de la constelación COPERNICUS para los años de 2019 y 2021. Estas imágenes fueron descargadas usando la herramienta GloVis del Servicio Geológico Americano (USGS), y la base de datos de Google Earth Engine.

La aplicación de técnicas de uso conjunto de datos provenientes de Landsat-8 y Sentinel-2, conceden escenas con mayor resolución temporal debido a que las áreas de estudio de cobertura glaciar son ampliamente caracterizadas por su alta nubosidad, obteniendo así imágenes de mejor calidad (Li y Roy, 2017; Singh et al., 2020; Andreassen et al., 2021). Además, al ser datos de libre acceso ofrecen la posibilidad de ser un medio eficaz para llevar a cabo análisis de áreas y coberturas (Wang et al., 2018). Una de las mayores ventajas del conjunto de datos Landsat 4, 5 y 7 son sus imágenes históricas, al cual se acredita el registro más extenso de imágenes satelitales (Wulder et al., 2019), permitiendo realizar un análisis multitemporal de la cobertura glaciar en la SRC.

Adicionalmente, fueron utilizadas 5 escenas ópticas de alta resolución como datos de referencia: 3 escenas de Google Earth (2020), para los años de 2009, 2014 y 2017 de entre 1,0 a 3,0 m de resolución espacial dependiendo del mosaico; y 2 escenas de "Planet's high-resolution, analysis-ready mosaics of the world's tropics" provistas por la Iniciativa Internacional sobre Clima y Bosques de Noruega (NICFI) a través de la plataforma Planet (2020) de 4,77 m de resolución espacial y que corresponden a los años de 2016 y 2019. Durante enero del 2021 se llevó a cabo una salida de campo que permitió tomar puntos de control con el fin de corroborar las clases propuestas en la clasificación de las imágenes (área glaciar, sueloroca, vegetación y agua), empleando un sistema de posicionamiento global GPS con una precisión de $3 \mathrm{~m}$ para una localización confiable en tiempo real. A lo largo de aproximadamente $93 \mathrm{~km}$ de caminos en el área de estudio, se recopilaron 500 puntos de control 
del suelo (Ground Control Point-GCP) para validar la clasificación de la imagen Sentinel-2 MSI de 2021. La fase de campo estuvo restricta a los caminos permitidos al público y a la disponibilidad de guías locales para el acceso al Parque Nacional Natural Sierra Nevada El Cocuy.
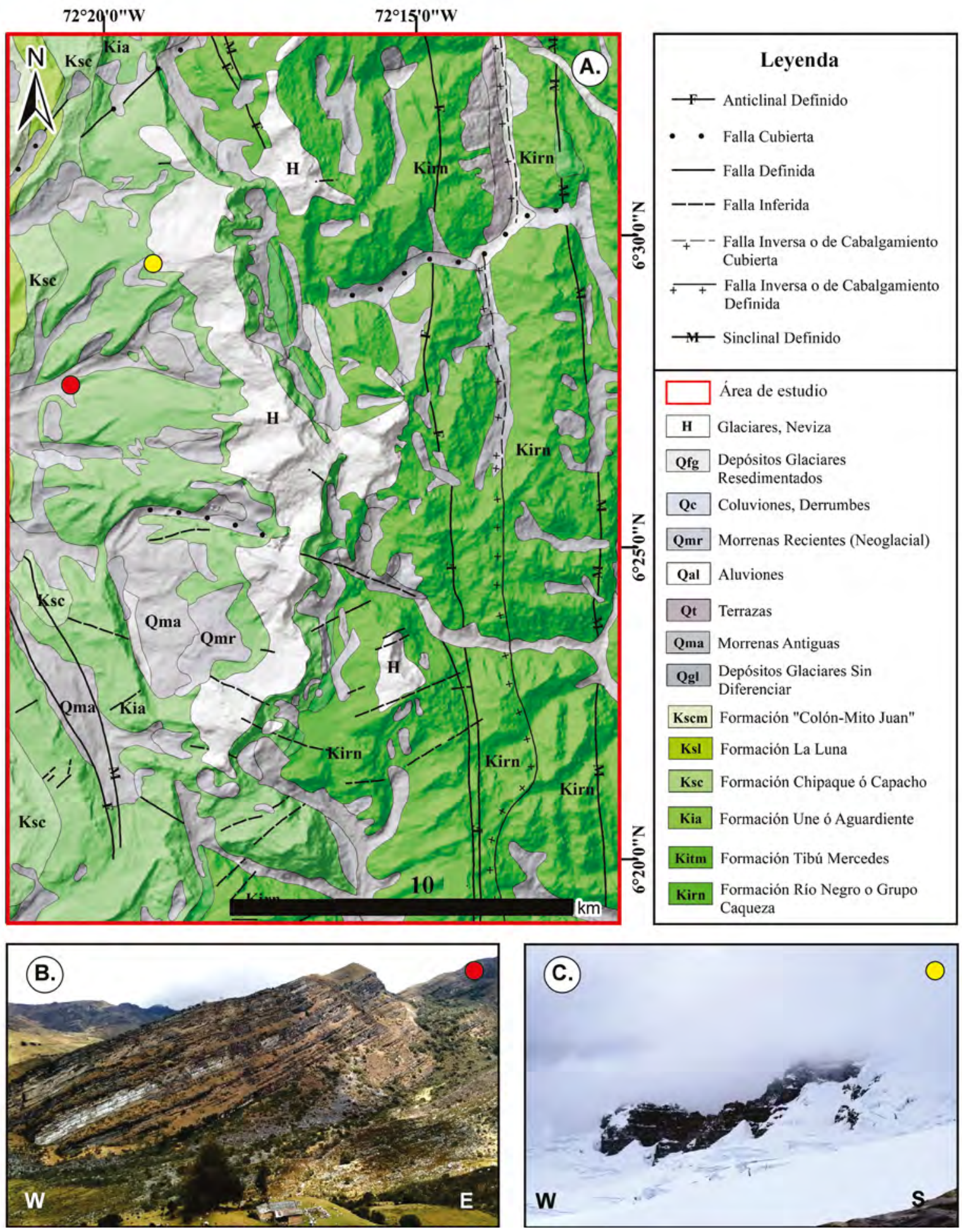

Figura 2. A. Mapa geológico (modificado de Fabre et al., 1984, 1985). B. Estratos buzantes de edad cretácica. C. Masa glaciar de la Sierra Nevada del Cocuy (SRC). 


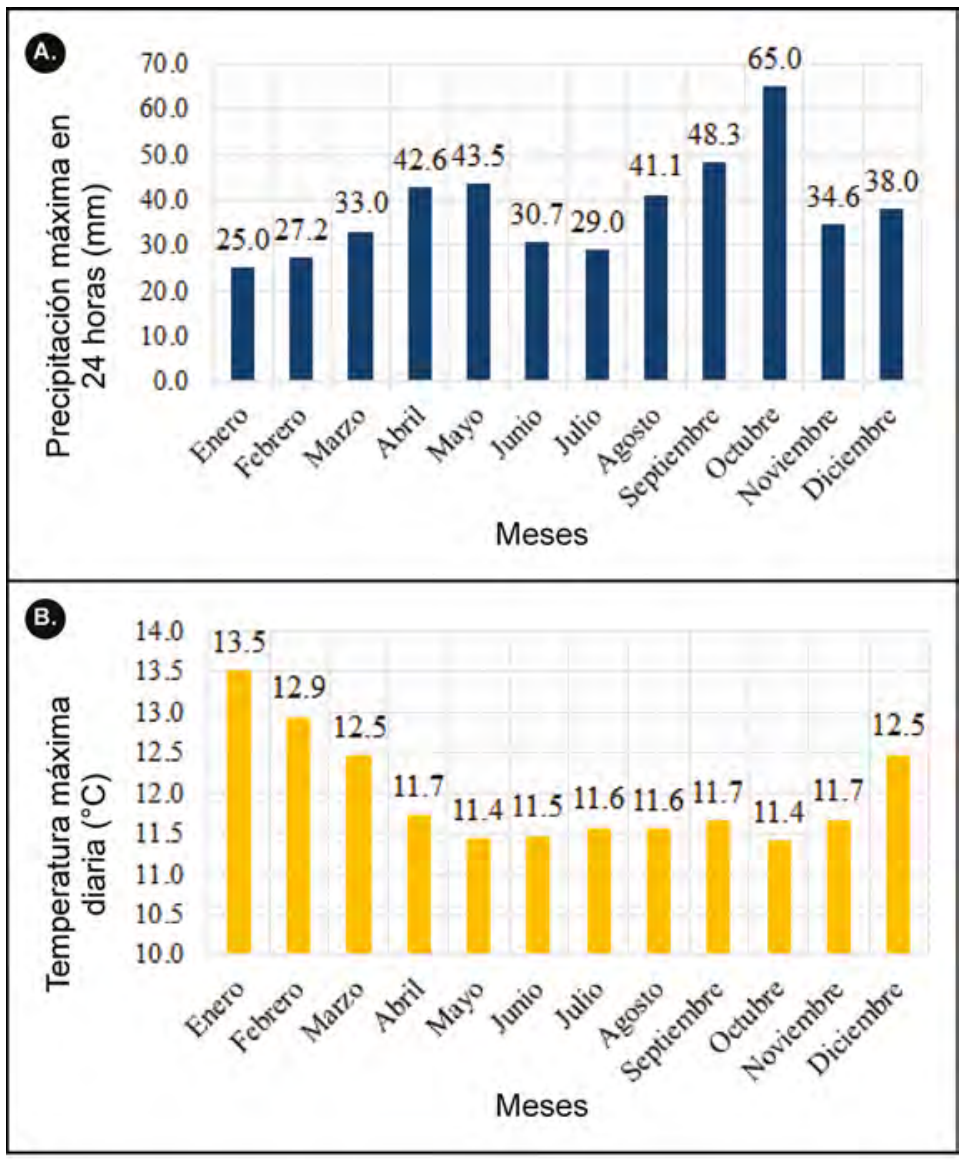

Figura 3. Valores máximos de precipitación y temperatura en 24 horas (1980-2020), estación Sierra Nevada del Cocuy. A. Precipitación máxima en 24 horas media mensual. B. Temperatura máxima diaria mensual en 24 horas.

\section{Procesamiento digital de las imágenes}

Cada una de las escenas procesadas, Landsat-4 (1987), Landsat-5 (1991, 1997, 2009), Landsat-7 (2000, 2003), Landsat-8 (2014, 2016, 2017), y Sentinel-2 (2019, 2021) se convirtieron de valores de número digital (DN) a reflectancia del suelo (GR). La conversión de las escenas se realizó en el módulo de corrección atmosférica (ATCOR) del Software PCI Geomatics 2016. Posteriormente, las imágenes de 1987 y 1997 fueron ortorrectificadas. Todas las imágenes de los diferentes sensores se remuestrearon a un tamaño de píxel de $30 * 30 \mathrm{~m}$ y se recortaron en función del área de estudio. Además, se crearon máscaras de nubes para las imágenes de los años 2003 y 2009 (únicas escenas que presentaron nubes) mediante mapeo manual, dibujando polígonos alrededor de las nubes evidenciadas en la composición RGB 7-4-3 para Landsat 5 y 7 (Tabla 1). En esta composición RGB se incluye una banda del infrarrojo de onda corta en el canal rojo. Para la nieve se debe tener en cuenta su alta absorción en el infrarrojo de onda corta (Domine et al., 2006), por lo cual en esta composición RGB 7-4-3, la cobertura de nieve se visualizará en color cian, mientras que las nubes se verán blancas. Utilizando estas máscaras se extrajeron los píxeles correspondientes a nubes, siendo excluidos durante la clasificación de las imágenes.

El índice NDSI propuesto por Dozier (1989), relaciona una banda del infrarrojo de onda corta y una del espectro visible. Para este estudio el índice NDSI fue calculado en todas las imágenes analizadas (Ecuación 1) (Figura 4). Las bandas escogidas para el cálculo de este índice en cada sensor fueron seleccionadas en función de su longitud de onda (Tabla 1), siendo consideradas como verde (Green) las bandas con longitudes de onda entre 0,5 y $0,6 \mu \mathrm{m}$, y como infrarrojo de onda corta $(S W I R)$ las bandas con longitudes de onda entre 1,55 y $1,75 \mu \mathrm{m}$.

$$
N D S I=\frac{\text { Green }-S W I R}{\text { Green }+S W I R}
$$


Sergio Mauricio Molano; Diana Paola Cardenas; Howard Snaider Gómez; Dayana Mairely Alvarado; Andrés Fernando Galindo; Jeisson Fabian Sanabria; Juan Sebastian Gómez-Neita

Tabla 1. Bandas usadas durante la clasificación para cada sensor, las unidades de longitud de onda se encuentran en $\mu \mathrm{m}$.

\begin{tabular}{|c|c|c|c|c|c|c|c|c|c|c|c|c|c|c|}
\hline \multicolumn{15}{|c|}{ Parámetros de clasificación } \\
\hline Satélite & Sensor & B1 & B2 & B3 & B4 & B5 & B6 & B7 & B8 & B9 & B10 & B11 & B12 & B8a \\
\hline Landsat-4 & ETM & - & $\begin{array}{c}0,52- \\
0,60\end{array}$ & $\begin{array}{c}0,63- \\
0,69\end{array}$ & $\begin{array}{c}0,76- \\
0,90\end{array}$ & $\begin{array}{c}1,55- \\
1,75\end{array}$ & - & - & - & - & - & - & - & - \\
\hline Landsat-5 & $\mathrm{TM}+\mathrm{MSS}$ & $\begin{array}{c}0,45- \\
0,52\end{array}$ & $\begin{array}{c}0,50- \\
0,60\end{array}$ & $\begin{array}{c}0,63- \\
0,69\end{array}$ & $\begin{array}{c}0,76- \\
0,90\end{array}$ & $\begin{array}{c}1,55- \\
1,75\end{array}$ & $\begin{array}{c}10,4- \\
12,5\end{array}$ & $\begin{array}{c}2,08- \\
2,35\end{array}$ & - & - & - & - & - & - \\
\hline Landsat-7 & ETM+ & $\begin{array}{c}0,45- \\
0,52\end{array}$ & $\begin{array}{c}0,50- \\
0,60\end{array}$ & $\begin{array}{c}0,63- \\
0,69\end{array}$ & $\begin{array}{c}0,76- \\
0,90\end{array}$ & $\begin{array}{c}1,55- \\
1,75\end{array}$ & $\begin{array}{c}10,4- \\
12,5\end{array}$ & $\begin{array}{c}2,08- \\
2,35\end{array}$ & $\begin{array}{c}0,52- \\
0,90\end{array}$ & - & - & - & - & - \\
\hline Landsat-8 & $\begin{array}{l}\text { OLI + } \\
\text { TIRS }\end{array}$ & $\begin{array}{c}0,43- \\
0,45\end{array}$ & $\begin{array}{c}0,45- \\
0,51\end{array}$ & $\begin{array}{c}0,53- \\
0,59\end{array}$ & $\begin{array}{c}0,64- \\
0,67\end{array}$ & $\begin{array}{c}0,85- \\
0,88\end{array}$ & $\begin{array}{c}1,57- \\
1,65\end{array}$ & $\begin{array}{c}2,11- \\
2,29\end{array}$ & $\begin{array}{c}0,50- \\
0,68\end{array}$ & $\begin{array}{l}1,36- \\
1,38\end{array}$ & $\begin{array}{l}10,6- \\
11,19\end{array}$ & $\begin{array}{l}11,5- \\
12,51\end{array}$ & - & - \\
\hline Sentinel-2 & MSI & $\begin{array}{c}0,43- \\
0,45 \\
\end{array}$ & $\begin{array}{c}0,45- \\
0,52 \\
\end{array}$ & $\begin{array}{c}0,54- \\
0,57\end{array}$ & $\begin{array}{c}0,65- \\
0,68 \\
\end{array}$ & $\begin{array}{c}0,69- \\
0,71 \\
\end{array}$ & $\begin{array}{c}0,73- \\
0,74 \\
\end{array}$ & $\begin{array}{c}0,77- \\
0,79 \\
\end{array}$ & $\begin{array}{c}0,78- \\
0,90\end{array}$ & $\begin{array}{c}0,93- \\
0,95 \\
\end{array}$ & $\begin{array}{l}1,36- \\
1,39 \\
\end{array}$ & $\begin{array}{c}1,56- \\
1,65\end{array}$ & $\begin{array}{l}2,10- \\
2,28 \\
\end{array}$ & $\begin{array}{c}0,85- \\
0,87 \\
\end{array}$ \\
\hline
\end{tabular}

Bandas usadas
Bandas no usadas

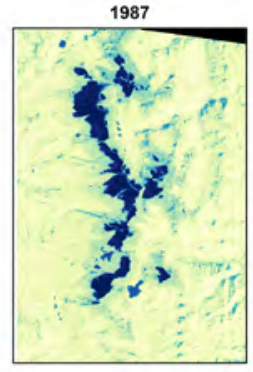

1991

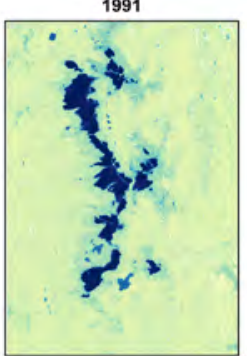

1997

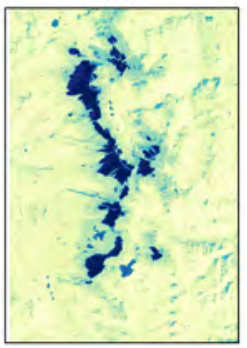

2000

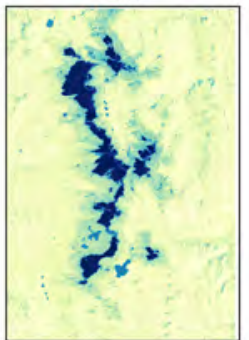

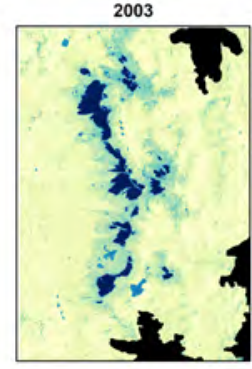

2009

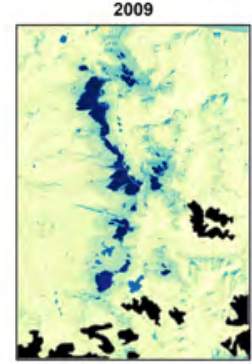

2014

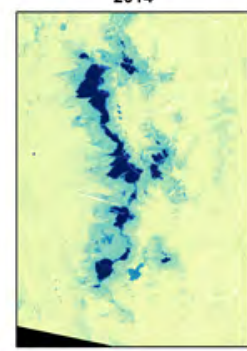

2016

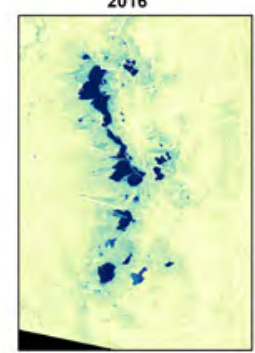

2017

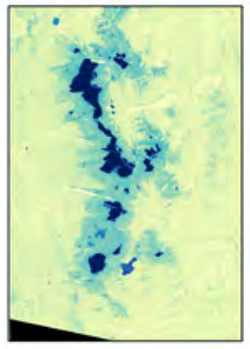

2019

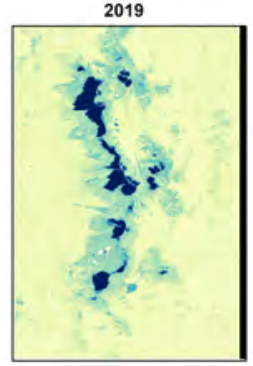

2021

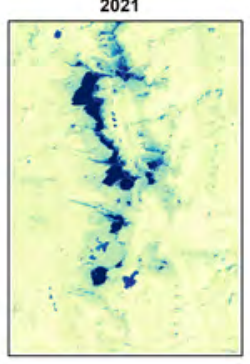

NDSI
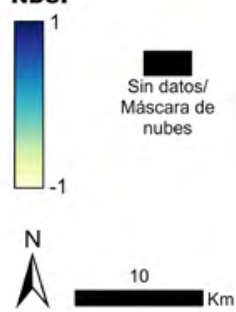

Figura 4. Distribución espacial del Normalized Difference Snow Index (NDSI) para las escenas de 1987, 1991, 1997, 2000, 2003, 2009, 2014, 2016, 2017, 2019 у 2021. 


\section{Clasificación supervisada orientada a píxel}

Se definieron 4 clases principales dentro del área de estudio (área glaciar, suelo-roca, vegetación y agua). Para la extracción estadística de las clases espectrales, se recolectaron al menos 25 muestras de polígonos de entrenamiento para cada clase ( $\sim 13341$ píxeles para el área glaciar, 48442 píxeles para suelo-roca, $\sim 1325$ píxeles para vegetación y $\sim 1621$ píxeles para agua). Las muestras de entrenamiento se definieron por clase, basados en los GCP colectados en campo, dibujando polígonos alrededor de los puntos mediante mapeo manual y considerando las variaciones correspondientes a cada año. Estos datos se complementaron con las imágenes de alta resolución. A pesar de la diferencia de hasta 40 años entre las imágenes y la adquisición de datos de campo, todas las descripciones de campo georreferenciadas y fotografiadas en el 2021 coincidieron en su mayoría con las clases observadas en las imágenes de años anteriores.

El dibujo de estos polígonos de muestreo se realizó a partir de una composición color RGB 5-4-3 para los sensores ETM, TM y ETM+, RGB 6-5-4 para el sensor OLI y RGB 11-8-4 para el sensor MSI. Posteriormente, se definieron las bandas que fueron usadas para la clasificación de cada escena, incluyendo valores de reflectancia de la región del visible y del infrarrojo cercano (Tabla 1), así como el índice NDSI (Metsämäki et al., 2015). Se empleó el modelo de clasificación de máxima verosimilitud, el cual mostró resultados más acordes con los datos de referencia. Este algoritmo clasifica las imágenes utilizando un proceso de cálculo interactivo, garantizando la máxima diferenciación estadística posible basada en los datos espectrales (Rodrigues y Souza-Filho, 2011).

\section{Evaluación de la exactitud de la clasificación}

Para evaluar la exactitud de la clasificación supervisada, se adoptó un modelo de matriz de confusión normalizada y estadística Kappa. Un total de 500 GCP fueron utilizados para evaluar la exactitud de la clasificación de la imagen de 2021 (dando un enfoque principal a la cobertura del área glaciar) (Figura 5). Para evaluar la exactitud de las clasificaciones de los años 2019, 2017, 2016, 2014 y 2009 se emplearon las imágenes de referencia de Google Earth y Planet con 500 puntos de validación localizados de manera aleatoria y estratificados de acuerdo al área de cobertura de cada clase con respecto a la escena total ( $\sim 250$ para el área glaciar, $\sim 150$ para el suelo-roca, $\sim 30$ vegetación y $\sim 70$ de agua). Debido a que las clasificaciones de las imágenes más antiguas no tenían disponibles datos de referencia (1987, 1991, 1997, 2000, y 2003), se usaron las mismas imágenes de Landsat 4, 5 y 7 en el proceso de evaluación de exactitud, generando 500 puntos de validación distribuidos aleatoriamente por toda la escena (Figura 5).

Para cada imagen de Landsat y Sentinel-2 fueron calculadas la exactitud de usuario y productor, exactitud global e índice Kappa individual con el fin de definir la concordancia de los datos (Congalton y Green, 2008; Santos et al., 2020). El uso del índice Kappa en este estudio tiene el fin de enriquecer la evaluación de exactitud de las clasificaciones. Aunque este índice sea discutido (Pontius y Millones, 2011), varias investigaciones actuales emplean el índice Kappa como referencia para la validación del mapeo de áreas con cobertura glaciar (e.g., López-Moreno et al., 2020; Sood et al., 2021; Zhang et al., 2020).

\section{Datos Climáticos}

Se evaluaron los valores medios anuales de precipitación y temperatura accedidos a través de la plataforma del Atlas climatológico de Colombia del IDEAM. Esta plataforma ofrece datos medidos reportados por una o dos estaciones meteorológicas por departamento, desde 1981 hasta el 2010, y la posibilidad de acceder a servicios de mapas interactivos. A partir de dichos valores se estableció de manera general la dinámica de los parámetros meteorológicos para el área de estudio y su repercusión en las tasas de retroceso glaciar para la SRC.

\section{Resultados}

\section{Clasificación general y evaluación de la exactitud de mapas multitemporales}

La clasificación supervisada para las imágenes de Landsat y Sentinel-2, fue basada en 4 clases (área glaciar, suelo-roca, vegetación y agua), que contienen características distintivas, utilizando los beneficios de cada tipo de datos. Esto permite aprovechar la complementariedad de los datos espectrales para extraer más información y permitir una identificación más clara entre las diferentes clases (Ducrot et al., 2010). En la Figura 6 se muestran las clases definidas en la zona de estudio y los valores correspondientes de área (ha) durante los años 1987, 1991, 1997, 2000, 2003, 2009, 2014, 2016, 2017, 2019 у 2021. El retroceso glaciar se hace más evidente sobre la vertiente occidental de la SRC (Herrera y Ruiz, 2008), donde progresivamente la clase correspondiente al área glaciar cambia a la clase suelo-roca. Las otras clases no presentan una relación de cambio evidente entre los diferentes periodos de tiempo. 


\begin{tabular}{cccc}
\hline Clases & $\begin{array}{c}\text { Imagen en } \\
\text { falso color }\end{array}$ & $\begin{array}{c}\text { Imagen de alta } \\
\text { resolución }\end{array}$ & $\begin{array}{c}\text { Fotografía de } \\
\text { campo }\end{array}$ \\
Área \\
glaciar
\end{tabular}

\section{Descripción}

Hielo y nieve con

coloraciones azules claras a blancas. Se localiza en las zonas

topográficamente más altas en alturas superiores a los $4800 \mathrm{msnm}$.

Afloramientos de rocas sedimentarias y suelos expuestos. También,

corresponde con depósitos cuaternarios de origen glaciar que debido al deshielo se encuentran expuestos actualmente.

Engloba áreas con presencia de vegetación de tipo arbórea y arbustiva Incluye parcialmente la vegetación de páramo cuando posee una

densidad que puede ser detectada por el sensor.

\begin{tabular}{ccc} 
Corresponde & $1987: 69$ & $2014: 70$ \\
principalmente con lagos & $1991: 70$ & $2016: 71$ \\
asociados a páramos y & $1997: 70$ & $2017: 70$ \\
glaciares. & $2000: 70$ & $2019: 70$ \\
& $2003: 70$ & $2021: 70$ \\
& $2009: 71$ & \\
\hline
\end{tabular}

Puntos para validación

1987: 249 2014: 250

1991: 250 2016: 251

1997: 250 2017: 250

2000: 250 2019: 250

2003: 250 2021: 250

2009: 250

1987: 152 2014: 148 1991: 150 2016: 152 1997: 150 2017: 150 2000: 150 2019: 142 2003: 150 2021: 150 2009: 154

1987: 30

1991: 30

1997: 30

2000: 30

2003: 30

2009: 25

2014: 32 2016: 26 2017: 30 2021: 30
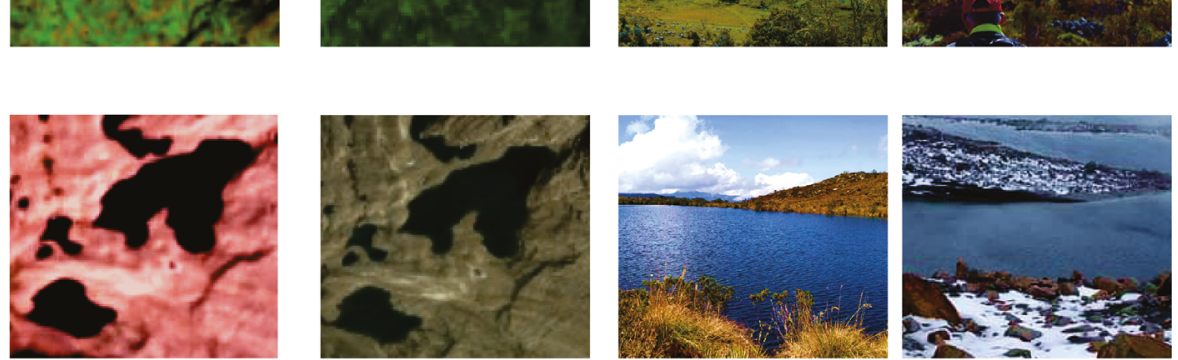
Las exactitudes globales de todas las escenas clasificadas son superiores al $86 \%$ (Tabla 2), mientras que los índices Kappa son superiores a 0,76. Generalmente, el índice Kappa para cada clase es superior a 0,7 excepto para la vegetación en las imágenes del 2009 y el 2017, y para la clase de suelo-roca en el 2009 (Figura 7A). Estos valores indican que el desacuerdo general es muy bajo y que las clases presentan un alto nivel de concordancia (Souza-Filho et al., 2018). La exactitud del productor es normalmente superior al $80 \%$, excepto para las clases de agua y vegetación en algunas de las imágenes (1987, 2000, 2009, 2016 y 2017) (Figura 7B). A pesar de esto, los valores para el área glaciar, foco de este estudio, estuvieron siempre por encima de $96,4 \%$. En cuanto a la exactitud del usuario, esta se mantuvo por encima del $80 \%$ con excepción de las coberturas de suelo-roca, agua y vegetación para las imágenes del 2009, 2016 y 2017 (Figura 7C). No obstante, dicha exactitud para la clase de área glaciar presentó valores superiores a 96,5\% (Figura 7C).

\section{Análisis de cambios multitemporales}

Los resultados de clasificación exhibieron un mayor valor de cobertura glaciar en la escena de 1987 con un área aproximada de 2899,6 ha (Tabla 3). De igual forma la clase de suelo-roca expuesta es dominante en todas las imágenes ( $>50 \%$ de cobertura), debido a las condiciones topográficas del área de estudio, substrato y clima. Desde 1987 hasta el 2021 la SRC exhibe variación en cuanto a las clases definidas anteriormente, lo cual puede relacionarse con el crecimiento temporal de vegetación durante las estaciones más húmedas y fusión glaciar, cambiando durante todos los intervalos de tiempo.

La clase de área glaciar presenta valores mínimos para el año 2009 con un área aproximada de 1488,6 ha, no obstante, y respecto a la siguiente escena (2014) existe ganancia de área glaciar en este periodo de tiempo (Figura 6). Dicho valor es aproximadamente 300 ha menor al que se registró en la última escena analizada (2021) (Tabla 3); sin embargo, cabe resaltar que los valores altos de cobertura glaciar ( $1800 \mathrm{ha})$ que presenta la imagen del 2021 están sujetos a la nevada registrada en la SRC en enero del mismo año. Esta nevada según reportes locales se derritió parcialmente y se acumuló únicamente en las zonas topográficamente más elevadas, por tal motivo puede que no genere datos representativos relacionados con el aumento de la masa glaciar para las imágenes analizadas posteriormente.
La Figura 8 muestra el área glaciar en la SRC para las 11 imágenes analizadas. Los valores exhiben normalmente un patrón decreciente, con cambios en las tasas de fusión glaciar en los diferentes intervalos de tiempo. Según el IDEAM (2001), este retroceso toma lugar principalmente en los bordes del glaciar con una tasa aproximada de pérdida de $15 \mathrm{~m} /$ año. Pese a esta tendencia, no pueden descartarse los valores de ganancia de área glaciar durante intervalos específicos (e.g., 2009-2014, 2019-2021). Esto indica la posible incidencia de los valores más bajos de exactitud durante la clasificación del 2009 y que la variación en el área glaciar de la SRC corresponde también con otros factores climáticos, los cuales no son constantes a lo largo del tiempo como por ejemplo grandes anomalías en el fenómeno de El Niño y La Niña.

En cuanto al cambio en las coberturas, el aumento del área glaciar en el período 2009-2014 se debe a un incremento en el régimen de lluvias asociado al fenómeno de La Niña. Se puede apreciar que el área glaciar se convirtió principalmente en la clase sueloroca, lo cual se confirma por los amplios depósitos de morrenas que se encuentran circundando actualmente la SRC (Figuras 2 y 5). De igual forma, se observa que la mayor pérdida de área glaciar se presenta sobre la vertiente occidental, además, las áreas glaciares de pequeña extensión prácticamente desaparecieron.

\section{Condiciones meteorológicas}

La zona de estudio presenta un ciclo anual bimodal en la precipitación (Poveda et al., 2006; Rekowsky et al., 2018), que depende en gran medida del comportamiento de la ZCIT, en la que los vientos alisios del NE y SE, con sus masas de aire cálido y cargados de humedad chocan entre sí en la cordillera. Allí se condensan y precipitan hacia la vertiente oriental de la SRC, creando un efecto de sombra hacia la parte occidental de la cordillera, determinando así el régimen de lluvias (Muñoz et al., 2005). Existe una clara diferenciación entre el régimen pluviométrico del costado oriental y occidental de la Cordillera Oriental. La región oriental de la SRC tiene un régimen de lluvias monomodal (Figura 9A) y bastante estacional principalmente hacia las sabanas, con un periodo de lluvias entre abril y noviembre y uno seco entre diciembre y marzo. Este comportamiento se debe a que esta zona recibe mayor influencia de los alisios del NE, por lo que en la época de invierno del hemisferio norte el aire viene frío y, por tanto, con baja humedad. 


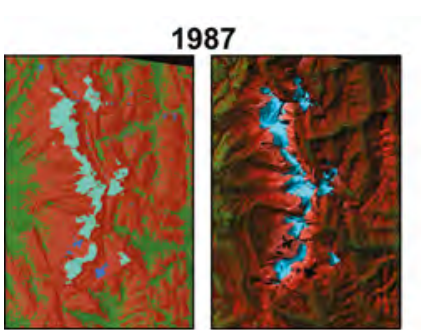

1991

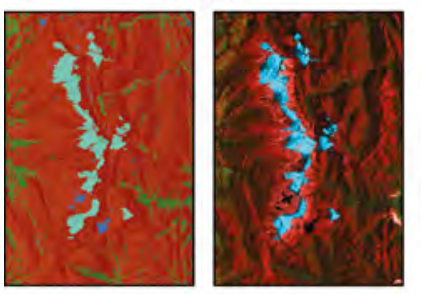

1997

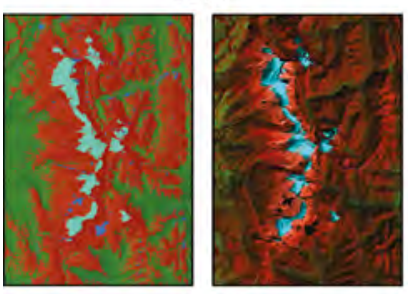

2000

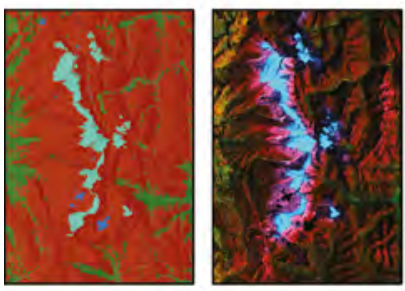

2003

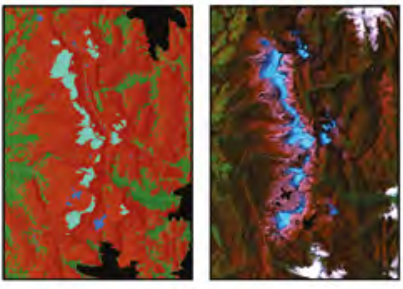

2009
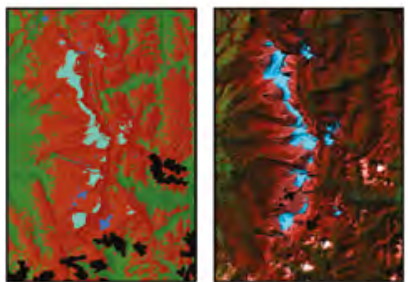

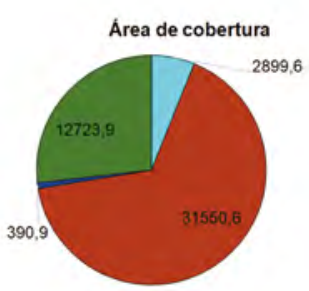

Área de cobertura

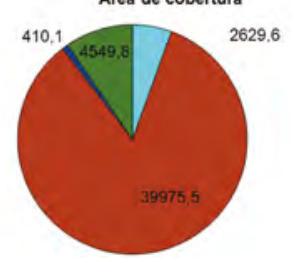

Área de cobertura
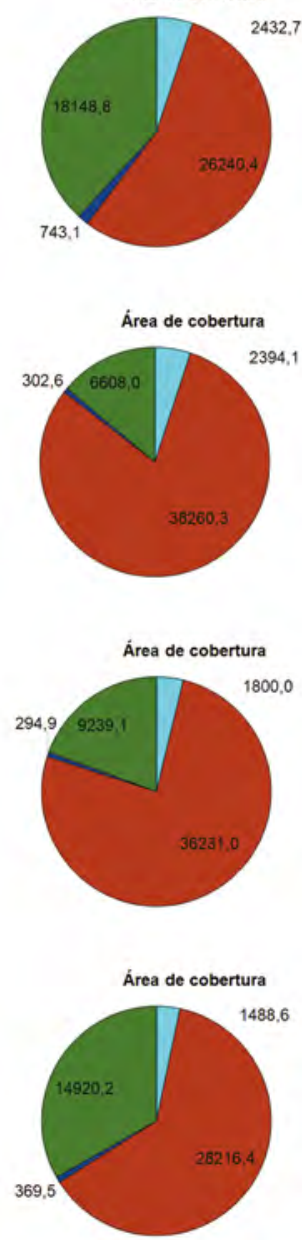

2014

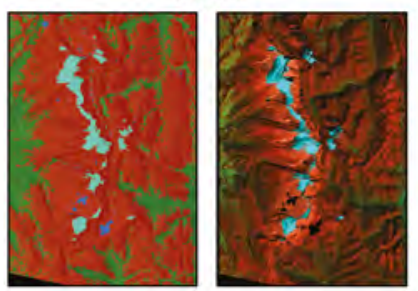

2016
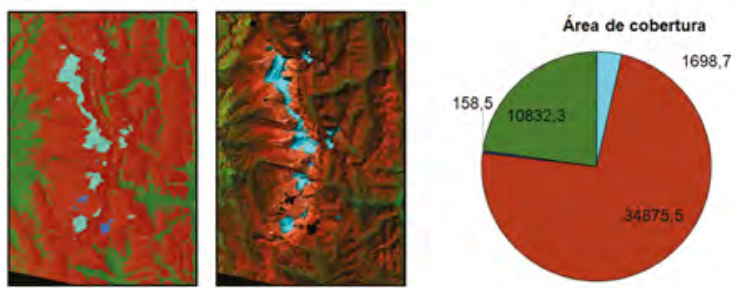

2017
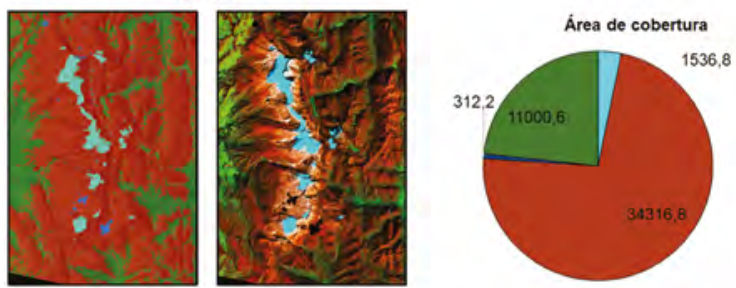

2019
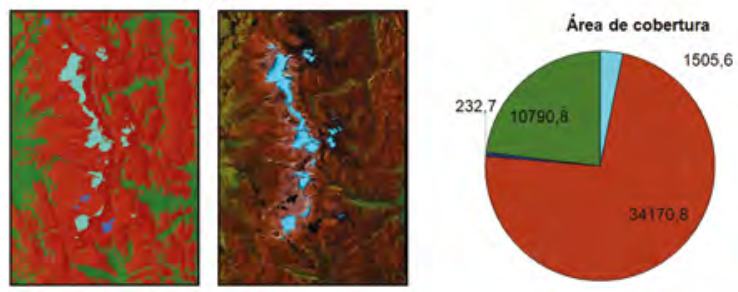

2021
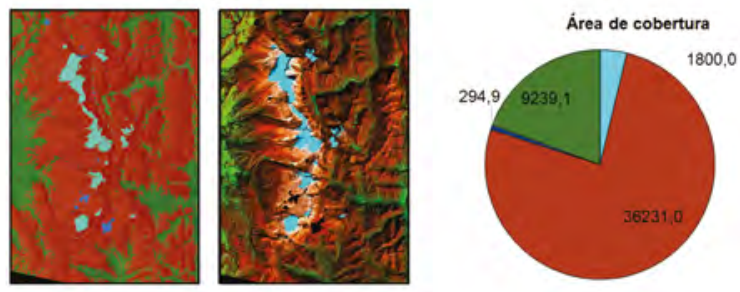

Sin datos/

Máscara de nubes

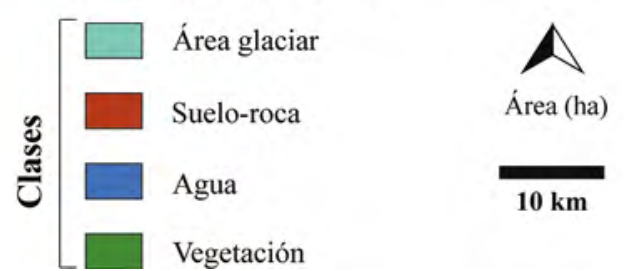

Figura 6. Imágenes clasificadas de Landsat y Sentinel-2 que muestran las variaciones temporales y espaciales para la Sierra Nevada del Cocuy (SRC) en los años 1987, 1991, 1997, 2000, 2003, 2009, 2014, 2016, 2017, 2019 y 2021. 
Tabla 2. Fechas de adquisición de las imágenes analizadas y exactitud global de las clasificaciones.

\begin{tabular}{ccc}
\hline Sensor & $\begin{array}{c}\text { Fecha de adquisición } \\
\text { dd/mm/aa }\end{array}$ & Exactitud global (\%) \\
\hline Landsat 4 MSS & $26 / 12 / 1987$ & 94,0 \\
Landsat 5 MSS + TM & $16 / 03 / 1991$ & 98,0 \\
Landsat 5 MSS + TM & $13 / 12 / 1997$ & 99,0 \\
Landsat 7 ETM+ & $13 / 02 / 2000$ & 95,0 \\
Landsat 7 ETM+ & $09 / 03 / 2003$ & 99,0 \\
Landsat 5 MSS + TM & $14 / 12 / 2009$ & 86,0 \\
Landsat 08 OLI & $10 / 01 / 2014$ & 97,0 \\
Landsat 08 OLI & $16 / 01 / 2016$ & 90,4 \\
Landsat 08 OLI & $20 / 12 / 2017$ & 87,0 \\
Sentinel-2 MSI & $25 / 02 / 2019$ & 95,0 \\
Sentinel-2 MSI & $15 / 01 / 2021$ & 97,0 \\
\hline
\end{tabular}

A.

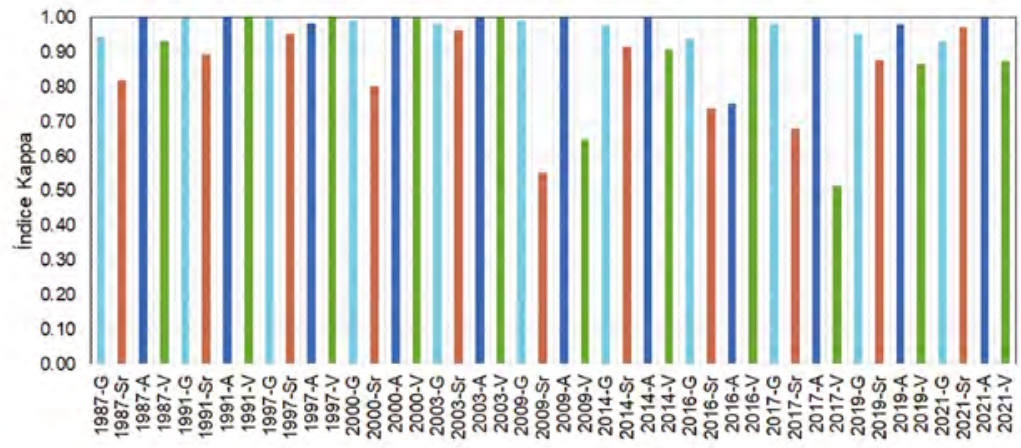

B.

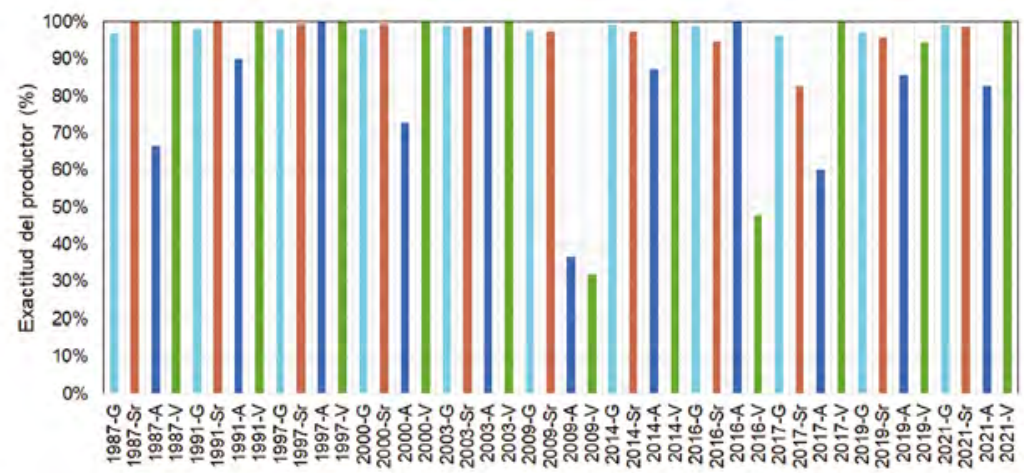

c.

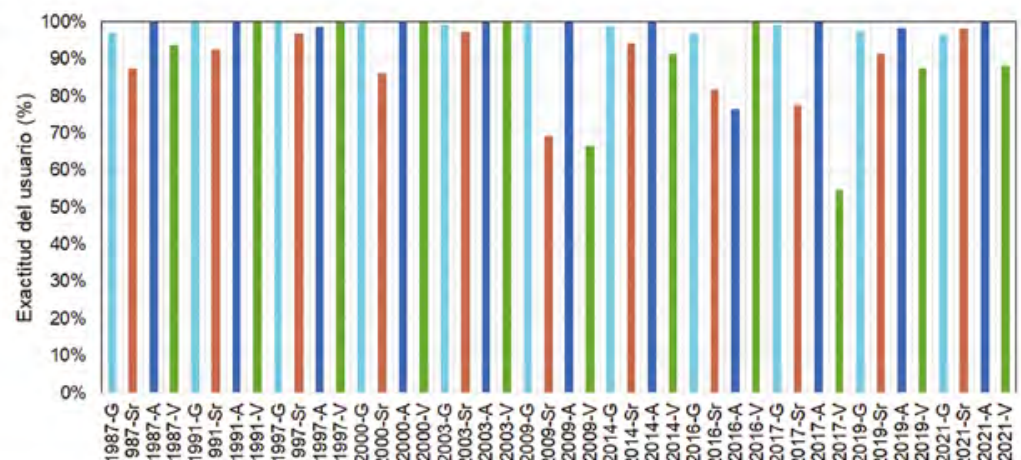

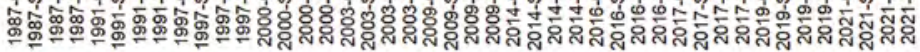

\section{Área glaciar (G)}

Suelo-roca (Sr)

\section{Agua (A)}

\section{Vegetación (V)}

Figura 7. A. Índice Kappa. B. Exactitud del productor. C. Exactitud del usuario. Datos presentados por cada clase para las imágenes de 1987, 1991, 1997, 2000, 2003, 2009, 2014, 2016, 2017, 2019 y 2021. 
Tabla 3. Valores de cobertura glaciar Sierra Nevada del Cocuy (SRC) basado en las escenas analizadas en este estudio.

\begin{tabular}{cccccc}
\hline Periodo & Área inicial (ha) & Área final (ha) & Años & Retracción (\%) & $\begin{array}{c}\text { Cambio de cobertura de área } \\
\text { glaciar (ha) (1987-2021) }\end{array}$ \\
\hline $1987-1991$ & 2899,6 & 2629,6 & 4,0 & 9,3 & $-270,0$ \\
$1991-1997$ & 2629,6 & 2432,7 & 6,0 & 7,5 & $-196,9$ \\
$1997-2000$ & 2432,7 & 2394,1 & 3,0 & 1,6 & $-38,6$ \\
$2000-2003$ & 2394,1 & 1800,0 & 3,0 & 24,8 & $-594,1$ \\
$2003-2009$ & 1800,0 & 1488,6 & 6,0 & 17,3 & $-311,4$ \\
$2009-2014$ & 1488,6 & 1750,5 & 5,0 & $-17,6$ & $-51,9$ \\
$2014-2016$ & 1750,5 & 1698,7 & 2,0 & 3,0 & $-161,9$ \\
$2016-2017$ & 1698,7 & 1536,8 & 1,0 & 9,5 & -31.2 \\
$2017-2019$ & 1536,8 & 1505,6 & 2,0 & 2,0 & 294,4 \\
$2019-2021$ & 1505,6 & 1800,0 & 2,0 & $-19,6$ & - \\
2021 & 1800 & - & - & 1,1 \\
\multicolumn{7}{c}{ Tasa de retracción anual (\%) } \\
Pérdida total (ha)
\end{tabular}

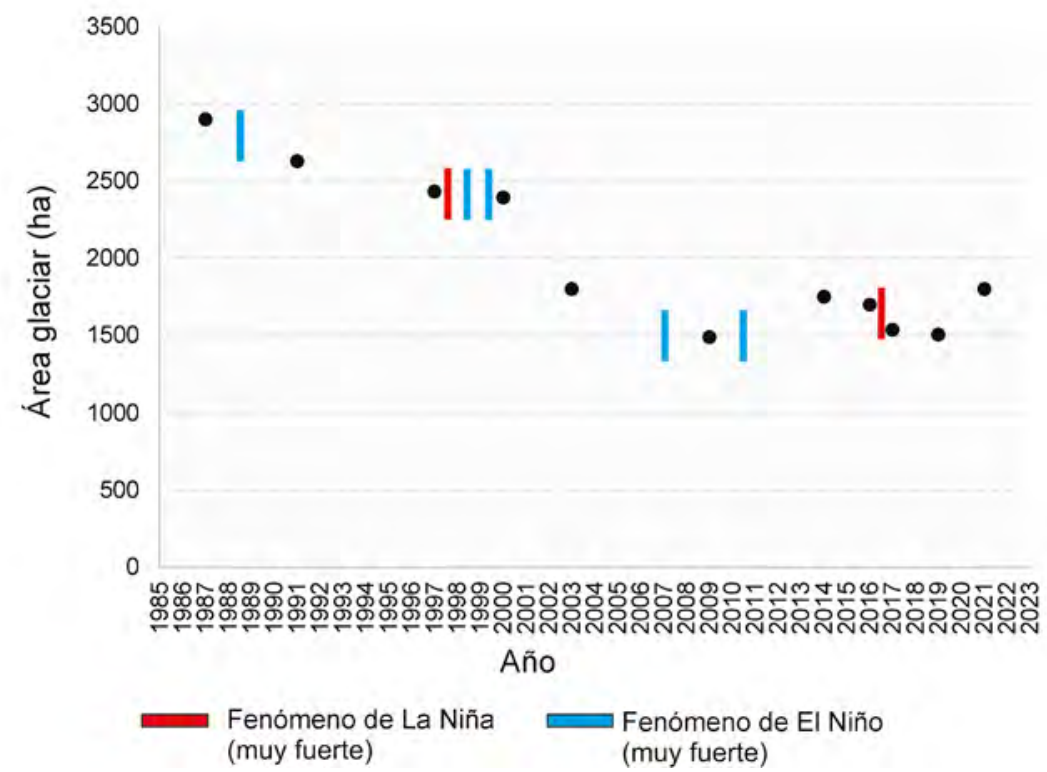

Figura 8. Cambios en el área glaciar de la Sierra Nevada del Cocuy (SRC) en el intervalo 1987-2021.

El régimen de lluvias hacia el occidente de la SRC es bimodal (Figura 9B), por el movimiento de la ZCIT. Los periodos húmedos ocurren entre abril-mayo y septiembre - octubre, cuando la ZCIT está pasando sobre la región, y los periodos secos entre diciembre marzo y junio - julio, cuando está en su posición más meridional y septentrional respectivamente (Muñoz et al., 2005). El flanco occidental del área cubre los municipios de El Cocuy, Chita, Chiscas y parte de Güicán. Este flanco se localiza en una sombra de lluvia o sotavento, por lo que en general la precipitación es menor en la vertiente occidental al no recibir la influencia directa de los alisos (Muñoz et al., 2005), lo que explica por qué el retroceso glaciar se presenta principalmente en esta vertiente.
De igual forma, las altas montañas en los Andes colombianos se caracterizan por poseer un clima frío con fluctuaciones en los valores medios de temperatura anual, brillo solar y humedad relativa, esta última al parecer con valores más altos en cercanías a la SRC (Figura 10) (Silva, 2010; IDEAM, 2012; Rekowsky et al., 2018). A pesar de que para Colombia los datos meteorológicos exhiben un aumento en los valores medios anuales de precipitación, las estaciones cercanas a la SRC revelan una tendencia de disminución en los valores de precipitación y un aumento significativo en la temperatura en los últimos 30 años (Rekowsky et al., 2018). Así, se entiende que los procesos de fusión glaciar se relacionan con cambios climáticos en diferentes escalas temporales asociados con fenómenos de alta variabilidad climática como El Niño y La Niña. 

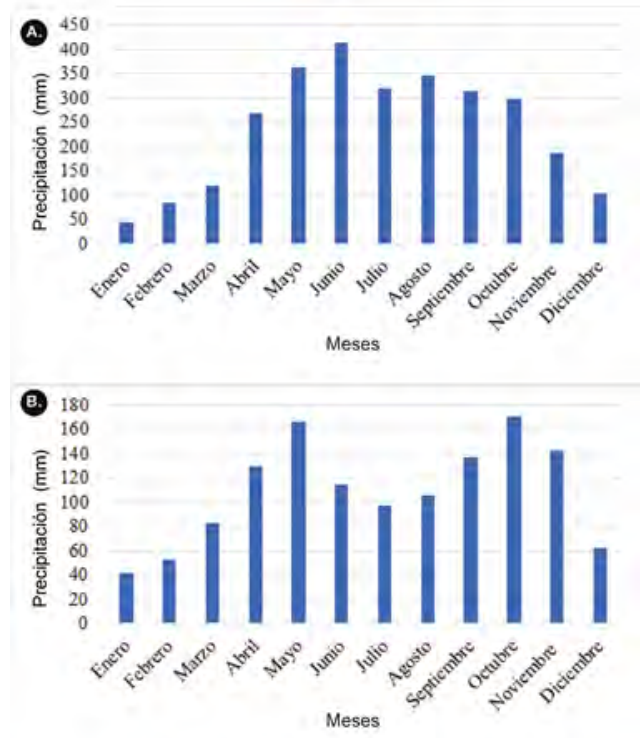

Figura 9. Valores de precipitación estaciones características de cada uno de los regímenes climatológicos, entre los años 20052009 de la SRC. A. Valores de precipitación mensual anual, estación Saravena - vertiente oriental. B. Valores de precipitación mensual anual, estación Chiscas - vertiente occidental. Modificado de Muñoz et al. (2005).

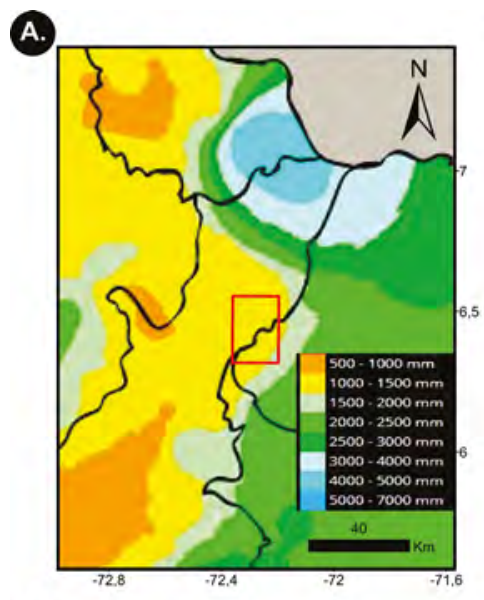

B.
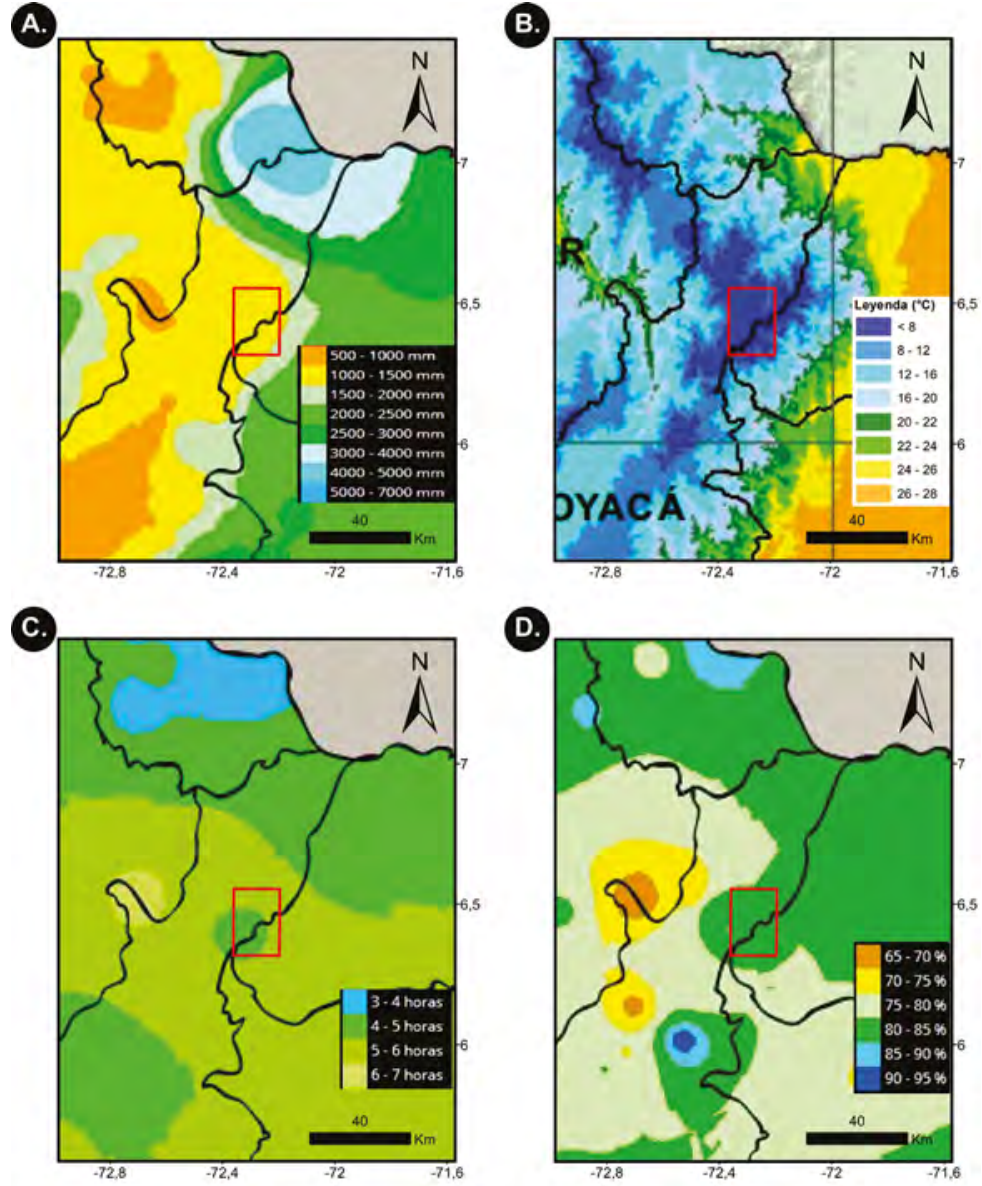

Figura 10. Principales factores meteorológicos en el área de estudio. A. Precipitación media anual. B. Temperatura media anual. C. Brillo solar media diaria anual. D. Humedad relativa media anual. La caja roja representa el área de estudio en la Sierra Nevada del Cocuy (SRC) (modificado de IDEAM (2010a)). 


\section{Discusión}

\section{Problemas de exactitud para las clases en el análisis multitemporal}

Las exactitudes obtenidas para las clasificaciones de las imágenes fueron satisfactorias, pero algunas consideraciones sobre el número y la distribución espacial de los puntos de control deben ser tomadas en cuenta. La recopilación de los GCP está restringida por la accesibilidad a la SRC y son relevantes únicamente para la escena del 2021. Dichos puntos se encuentran limitados a los bordes del glaciar y solo fueron tomados sobre la vertiente occidental, por tal motivo, la distribución espacial no es ideal estadísticamente. Debido a esto, es probable que algunos de los puntos presenten autocorrelación espacial haciendo que la concordancia media sea mayor (Guiot y de Vernal, 2011; Souza-Filho et al., 2018).

En cuanto a las otras escenas, la validación se efectuó apenas con imágenes de alta resolución disponibles para los años 2009, 2014, 2016, 2017 y 2019, lo que genera un mayor grado de incertidumbre en las imágenes adquiridas previamente a estos datos; sin embargo, los valores generales de exactitud sugieren que la estrategia de validación fue consistente para todas las imágenes. La exactitud global y el índice Kappa fueron calculados con la finalidad de medir el grado de concordancia con los puntos de control. No se llevó en consideración información sobre la naturaleza de los desacuerdos como son el de asignación y el cuantitativo, los cuales son importantes para considerar diferencias de áreas de clase entre dos escenas (Souza-Filho et al., 2018).

La exactitud del productor, así como el error de omisión, muestran qué tan bien fueron clasificados los puntos de control en las imágenes analizadas (Foody, 2002; Souza-Filho et al., 2018). De acuerdo con estos valores, las exactitudes del productor fueron similares en valor y con una tendencia uniforme especialmente para la cobertura de área glaciar, sin embargo, existen valores significativamente altos de error de omisión asociados a las clases de agua y vegetación. Esto puede deberse a la cantidad de puntos tomados para la validación de estas clases o a respuestas espectrales similares, como por ejemplo la encontrada entre la vegetación de páramo de pequeño porte y el suelo-roca. Esta consideración no representa problemática para este estudio debido a que el enfoque principal es cuantificar el área glaciar y en comparación a las demás clases, esta presentó los valores de exactitud más altos y de error más bajos $(<3 \%)$. Los valores de exactitud del usuario y el error de omisión indican qué tan genuinas son las clases definidas y la proporción de las diferentes clases que han sido asignadas respectivamente (Foody, 2002). Las medidas, a pesar de ser uniformes presentaron variación entre las clases y los años analizados (1987-2021), sugiriendo que en ocasiones ciertas clases incluían proporciones importantes de otras clases, lo cual ocurrió principalmente en la vegetación y el agua. Además, cabe resaltar que las imágenes usadas no presentan nubes sobre el área glaciar lo que corrobora la exactitud de los resultados obtenidos.

\section{Variación multitemporal del área glaciar}

En estudios previos, el mapeo del área glaciar en la SRC fue realizado empleando el NDSI el cual presenta una distinción representativa para la delimitación de áreas glaciares en comparación con las imágenes de composición colorida (Bautista y Correa, 2018; Rekowsky et al., 2018); sin embargo, en la mayoría de los casos este procedimiento responde a la creación de máscaras de nieve, y cálculo de las áreas correspondientes, lo cual limita los resultados a procesos de interpretación visual. La metodología usada en este estudio ofrece la posibilidad de incluir durante la clasificación una mayor cantidad de información espectral de las bandas de los sensores seleccionados, y no restringir la información del modelo de clasificación, únicamente a las bandas utilizadas en el índice NDSI. Las bandas espectrales permiten hacer una caracterización apropiada de las coberturas (Varade et al., 2017), facilitando la distinción entre las clases propuestas. La diferenciación entre la clase suelo-roca y la clase de área glaciar, se basa en un pico de reflectancia para la nieve en la longitud de onda del visible (Painter et al., 1998), y una alta absorción en el infrarrojo cercano (Domine et al., 2006); mientras, en la clase suelo-roca existe un pico de reflectancia en el infrarrojo cercano y en el infrarrojo de onda corta (Dong, 2018).

El problema en la delimitación del área glaciar radica principalmente en la resolución espacial de las imágenes usadas, pues debido al tamaño del píxel, cuerpos glaciares de pequeña extensión no se toman en consideración. Aun así, cuerpos menores a esta área de cobertura $\left(900 \mathrm{~m}^{2}\right)$ localizados en los bordes del glaciar, son más susceptibles a los efectos causados por los aumentos de temperatura y por ende tienden a presentar fusión, por lo que posiblemente no sean constantes a lo largo del tiempo e imperceptibles para la escala de estudio.

De acuerdo con Rekowsky et al. (2018) la retracción de las áreas glaciares en la SRC se presentó hacia los bordes del cuerpo glaciar, lo cual es coherente con los 
resultados obtenidos en este estudio (Figura 11). Dicha variación está relacionada con que estos bordes se encuentran normalmente en alturas más bajas, donde los valores de temperatura son mayores y el espesor de hielo no es significativo. Así, varios de los cuerpos glaciares que conforman la SRC enfrentaron un proceso de fragmentación, como ya había sido documentado anteriormente (Figura 11) (Herrera y Ruiz, 2008). En esta dinámica de retroceso es evidente que además de la disminución del área glaciar principal, se han extinto otros picos menores tales como el Alto Peña Colorada y la Sierra Nievesita, indicando que la extensión de los glaciares tropicales es un factor determinante en las tasas de retroceso (Florez, 1991; Herrera y Ruiz, 2008). De acuerdo con estudios sedimentológicos de las morrenas asociadas a la SRC, se indica que la extensión glaciar para 1850 era de aproximadamente 148700 ha (Figura 11) con una cobertura dominante sobre la vertiente occidental.

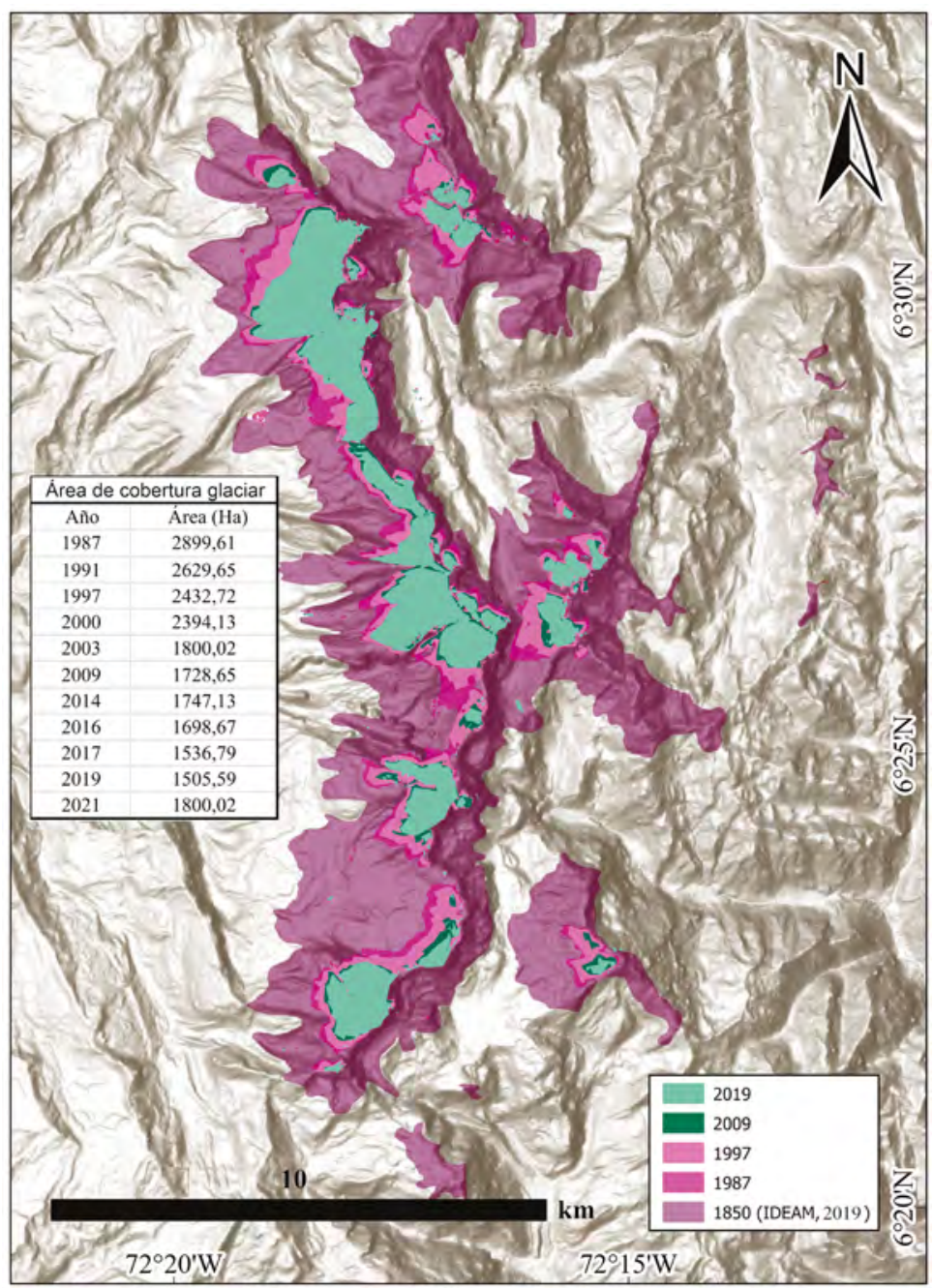

Figura 11. Variación del área glaciar de la Sierra Nevada del Cocuy (SRC) para los años 1850, 1987, 1997, 2009 y 2019.

Al occidente de la SRC se presentan pendientes más suaves, revelando que la topografía del terreno controla también el espesor de hielo y la estabilidad del glaciar (Figura 12), el cálculo de las pendientes permite definir que en áreas menos inclinadas de la SRC el hielo y la nieve se extienden favoreciendo su desplazamiento, mientras que en la vertiente oriental, se presentan pendientes más abruptas que acaban en depresiones, lo que permite la acumulación de la masa glaciar (IDEAM, 2001; Herrera y Ruiz, 2008). Según la tendencia de retroceso glaciar calculada por Herrera y Ruiz (2008), el glaciar de la SRC desaparecería aproximadamente en el año 2075, presentando mayores cambios en la vertiente occidental. Esta hipótesis concuerda con el trabajo de Quintero (2018) que define la existencia de corrientes húmedas sobre 
la vertiente oriental, la cual, a pesar de ser menor en extensión, parece ser más estable a lo largo del tiempo.

La SRC enfrenta un proceso de retroceso glaciar de acuerdo con estudios previos (Tabla 4), sin embargo, la tasa de retroceso es diferente para cada uno de estos, lo cual depende en gran medida de las imágenes seleccionadas, el tiempo de adquisición de las escenas, el método de interpretación, el intervalo de tiempo y las condiciones meteorológicas. Una ecuación lineal con pendiente negativa de $-46,195$, obtenida a través de la regresión generada con el conjunto de datos (Tabla 4, Figura 13) sugiere una tendencia de retroceso, presentando un coeficiente de determinación de $\sim 0,85$ lo cual indica que el modelo se ajusta muy bien a los datos analizados. Cabe resaltar que la mayor dispersión se presenta en las áreas calculadas antes de 1990 lo cual puede deberse a la disponibilidad de productos de sensores remotos (incluyendo la resolución espacial, espectral y temporal de estos) y la exactitud de los datos con que las áreas glaciares fueron calculadas cuando aún no se disponía de imágenes satelitales.

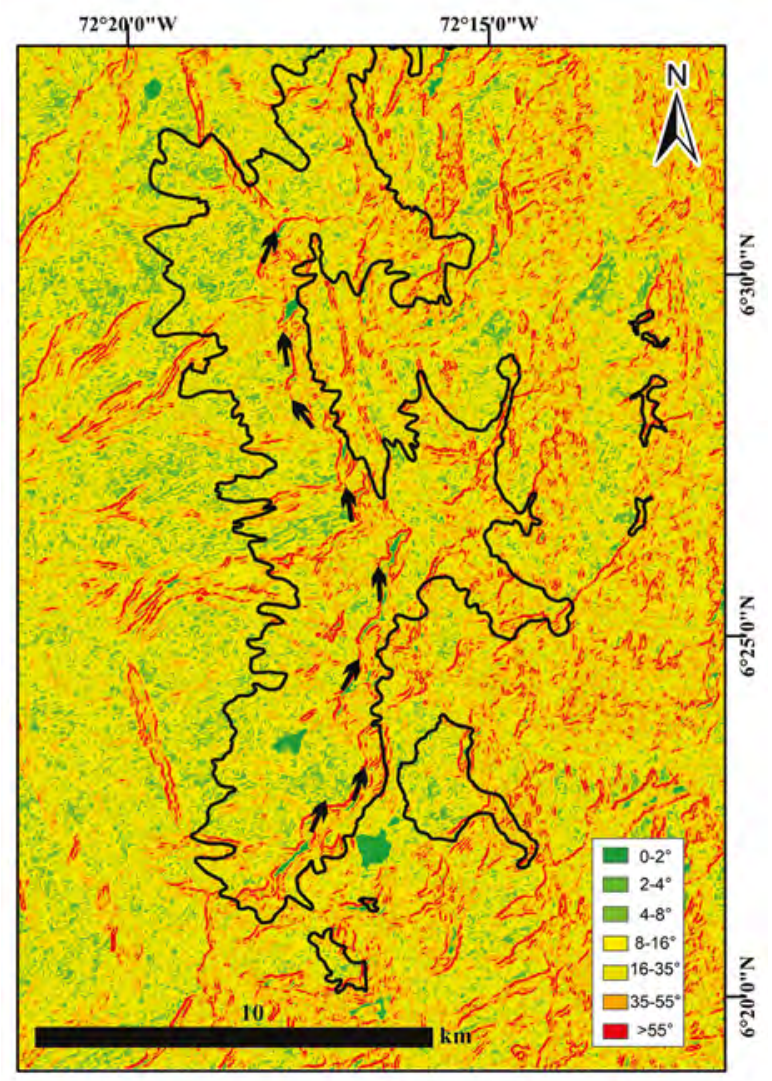

Figura 12. Mapa de pendientes de la Sierra Nevada del Cocuy (SRC).

De acuerdo con la tendencia de retroceso calculada a partir de todos los datos analizados en este estudio y los recopilados de otros autores (i.e., Florez, 1991; Guillen et al., 2004; Morris et al., 2006; Ceballos et al., 2006, 2010; Herrera y Ruiz, 2008; Peña, 2015; Bautista y Correa, 2018; Rekowsky et al., 2018) se estima que la SRC perderá toda su cobertura glaciar aproximadamente en el año 2048. Esto se ajusta con los resultados obtenidos por Guillen et al. (2004) y Morris et al. (2006) en las tasas de retroceso glaciar calculadas por Herrera y Ruiz (2008), en las que se prevé la desaparición del glaciar para los años 2053 y 2040 respectivamente. Si se tienen en cuenta únicamente los resultados obtenidos en este estudio, se prevé que la extinción del glaciar ocurrirá en el año 2058, lo cual concuerda perfectamente con los resultados obtenidos por Ceballos et al. (2006). A pesar de la concordancia en los valores encontrados de retroceso, no puede descartarse la incidencia de otros factores en las tasas de pérdida glaciar para la SRC. Por ejemplo, los datos obtenidos por Rodríguez (2015) indican variaciones en los valores de precipitación, los cuales junto con la temperatura, topografía y extensión del glaciar podrían acelerar o retardar las tasas de retroceso. Esto sugiere que el retroceso de la SRC no depende únicamente del tiempo transcurrido entre dos escenas analizadas, sino que incluye ciertos parámetros climáticos. 
Evaluación del retroceso glaciar de la Sierra Nevada del Cocuy, Colombia a partir de la clasificación de imágenes multisensor

Tabla 4. Valores de retroceso glaciar de la Sierra Nevada del Cocuy (SRC).

\begin{tabular}{|c|c|c|c|}
\hline Autor & Año & Área $\left(\mathbf{k m}^{2}\right)$ & Área (ha) \\
\hline \multirow{2}{*}{ Florez (1991) } & 1978 & 38,33 & 3833,00 \\
\hline & 1986 & 35,70 & 3570,00 \\
\hline \multirow{3}{*}{ Guillen et al. (2004) } & 1960 & 48,88 & 4888,00 \\
\hline & 1986 & 35,65 & 3565,00 \\
\hline & 2003 & 24,52 & 2452,00 \\
\hline \multirow{4}{*}{ Morris et al. (2006) } & 1959 & 39,12 & 3912,00 \\
\hline & 1973 & 28,00 & 2800,00 \\
\hline & 1999 & 20,39 & 2039,00 \\
\hline & 2003 & 16,30 & 1630,00 \\
\hline \multirow{4}{*}{ Ceballos et al. (2006) } & 1955 & 38,90 & 3890,00 \\
\hline & 1986 & 31,40 & 3140,00 \\
\hline & 1994 & 23,70 & 2370,00 \\
\hline & 2003 & 19,80 & 1980,00 \\
\hline \multirow{3}{*}{ Herrera y Ruiz (2008) } & 1986 & 28,13 & 2813,00 \\
\hline & 2003 & 20,79 & 2079,00 \\
\hline & 2007 & 17,15 & 1715,00 \\
\hline \multirow{8}{*}{ Ceballos et al. (2010) } & 1955 & 38,90 & 3890,00 \\
\hline & 1986 & 21,45 & 2145,00 \\
\hline & 1994 & 23,70 & 2370,00 \\
\hline & 2003 & 19,80 & 1980,00 \\
\hline & 2007 & 18,60 & 1860,00 \\
\hline & 2008 & 17,70 & 1770,00 \\
\hline & 2009 & 17,40 & 1740,00 \\
\hline & 2010 & 16,00 & 1600,00 \\
\hline \multirow{6}{*}{ Rekowsky et al. (2018) } & 1985 & 31,93 & 3193,00 \\
\hline & 2016 & 14,63 & 1463,00 \\
\hline & 1991 & 27,00 & 2700,00 \\
\hline & 1997 & 22,00 & 2200,00 \\
\hline & 2003 & 21,50 & 2150,00 \\
\hline & 2009 & 17,00 & 1700,00 \\
\hline \multirow{8}{*}{ Peña (2015) } & 1992 & 28,10 & 2810,00 \\
\hline & 1994 & 23,70 & 2370,00 \\
\hline & 2003 & 20,40 & 2040,00 \\
\hline & 2007 & 18,60 & 1860,00 \\
\hline & 2008 & 17,70 & 1770,00 \\
\hline & 2009 & 17,40 & 1740,00 \\
\hline & 2010 & 16,00 & 1600,00 \\
\hline & 2014 & 11,20 & 1120,00 \\
\hline \multirow{4}{*}{ Bautista y Correa (2018) } & 1987 & 29,36 & 2936,00 \\
\hline & 1997 & 23,33 & 2333,00 \\
\hline & 2009 & 17,39 & 1739,00 \\
\hline & 2015 & 15,27 & 1527,00 \\
\hline \multirow{11}{*}{ Este trabajo } & 1987 & 29,00 & 2899,60 \\
\hline & 1991 & 26,30 & 2629,60 \\
\hline & 1997 & 24,33 & 2432,70 \\
\hline & 2000 & 23,94 & 2394,10 \\
\hline & 2003 & 18,00 & 1800,00 \\
\hline & 2009 & 14,89 & 1488,60 \\
\hline & 2014 & 17,51 & 1750,50 \\
\hline & 2016 & 16,99 & 1698,70 \\
\hline & 2017 & 15,37 & 1536,80 \\
\hline & 2019 & 15,06 & 1505,60 \\
\hline & 2021 & 18,00 & 1800,00 \\
\hline
\end{tabular}




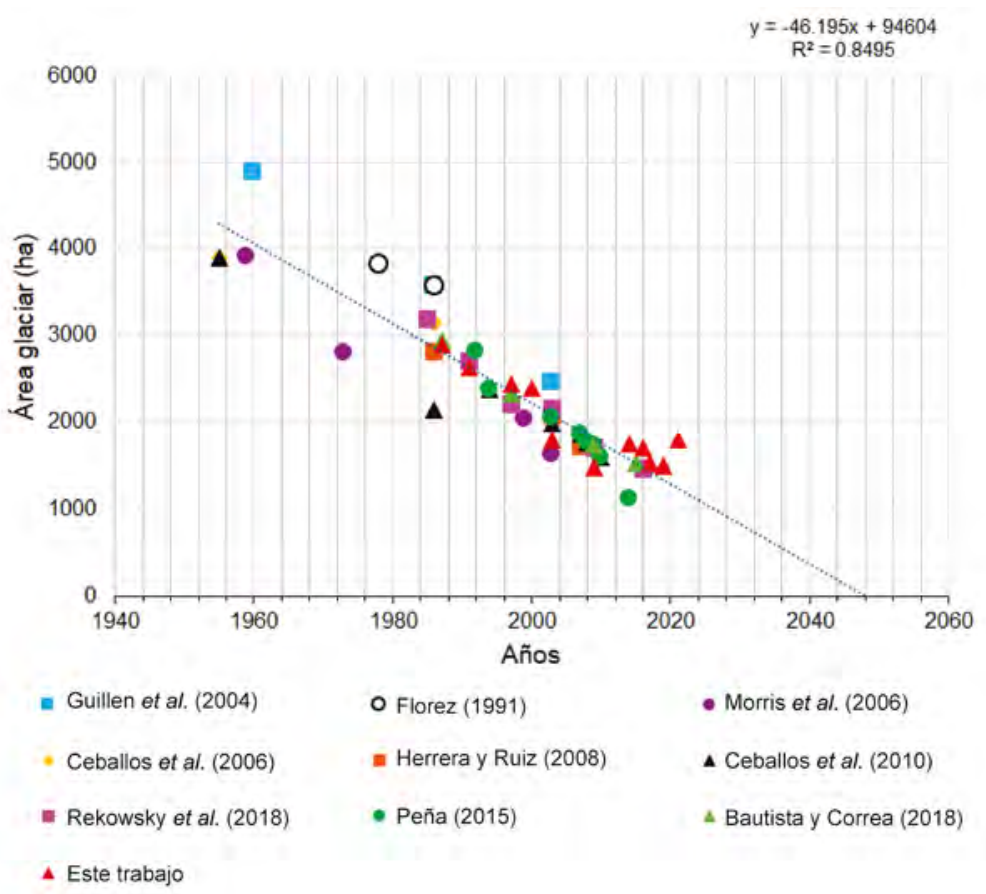

Figura 13. Retroceso glaciar de la Sierra Nevada del Cocuy (SRC) desde 1955-2021.

\section{Incidencia de los factores climáticos}

Los datos de referencia utilizados en este estudio para el año de 1850 (Figura 11) podrían asociarse a los efectos de la Pequeña Edad de Hielo. La Pequeña Edad de Hielo fue un periodo de enfriamiento en la Tierra, ocurrido entre 1600-1850 (Matthews y Briffa, 2005) caracterizado por cambios climáticos a escala regional, con efectos moderados en el hemisferio norte (Boretti, 2020). Los glaciares ecuatoriales registran el máximo glaciar en el siglo XVII, y un retroceso constante del área glaciar durante los siglos XVIII a XIX (Rabatel et al., 2005), esto es contrario a lo ocurrido en el hemisferio norte donde los glaciares continuaban expandiéndose en estos dos siglos (Rowan, 2017). Por lo tanto, no se puede asegurar una relación directa entre la Pequeña Edad de Hielo y los datos registrados por el IDEAM (2019) para la SRC.

Los valores medios anuales de temperatura y precipitación mostrados por el IDEAM (2010b) para la estación Sierra Nevada de El Cocuy sugieren variaciones importantes en estos parámetros climáticos desde 1974 hasta 2007. Así, se evidencia una disminución progresiva en las tasas medias de precipitación (Figura 14A) y un aumento en las temperaturas medias anuales (Figura 14B). Estas variaciones se relacionan directamente con el cambio climático, que normalmente exhibe esta tendencia de aumento de las temperaturas debido al calentamiento global y el efecto invernadero asociado (ValdezCepeda et al., 2003). Esta tendencia parece responder de manera más o menos lineal, aunque puede incluir a su vez ciertos parámetros de variabilidad climática que no se relacionan directamente con el cambio climático. Dentro de estos parámetros, la actividad de El NiñoSouthern Oscillation (ENSO) controla en gran medida los valores de precipitación y temperatura en la SRC, como resultado del enfriamiento y calentamiento de las aguas superficiales del pacífico, el debilitamiento de los vientos alisios en el este y el desplazamiento del núcleo de convección profunda (IDEAM, 2007).

El fenómeno de El Niño se considera como una época en la que predominan condiciones más secas y cálidas. Los años en los que se reportó una fuerte incidencia de El Niño, presentan grandes valores de retroceso glaciar en la SRC entre las escenas analizadas (e.g., 1987-1991, 1991-1997, 2000-2003, 2003-2009, 20142019) (Figura 14C). Por el contrario, periodos donde el fenómeno de La Niña fue más fuerte indican una recuperación del área glaciar (e.g., 2009-2014, 20192021) (Figura 14C), lo que se debe al predominio de condiciones más húmedas y mayores tasas de precipitación.

La variabilidad de la precipitación en los Andes tropicales está relacionada con la ocurrencia del ENSO, por lo cual el fenómeno de El Niño ocurrido 
en 1997/1998, indujo un balance de masa negativo debido a temperaturas más altas y a la reducción de las precipitaciones, seguido de un lento retroceso durante las fuertes condiciones de La Niña en 1999 (Ceballos et al., 2006). En el caso de los glaciares colombianos, un aumento en la temperatura del aire y la radiación solar fueron los principales mecanismos detrás del rápido
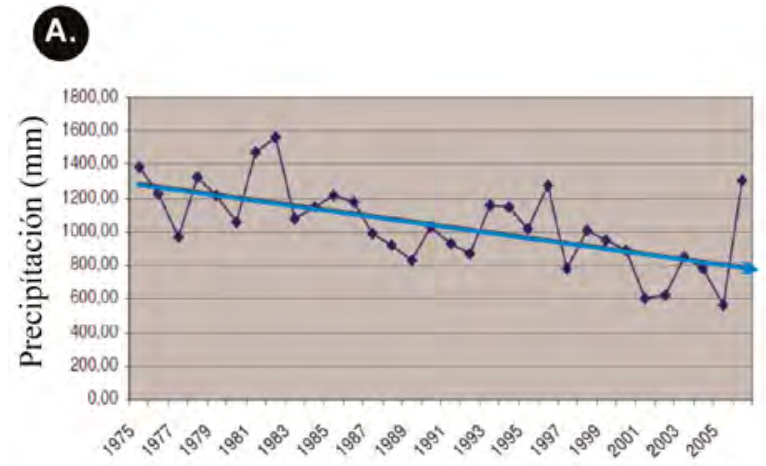

Años retroceso de los glaciares, más que los cambios en las precipitaciones (Euscategui, 2002). Este supuesto debe ser validado considerando el hecho de que un aumento de temperatura puede desencadenar un cambio en la fase de precipitación de sólido (nevadas) a líquido (lluvia), lo que a su vez favorece el retroceso de los glaciares por reducción del albedo (Veettil, 2017).
B.

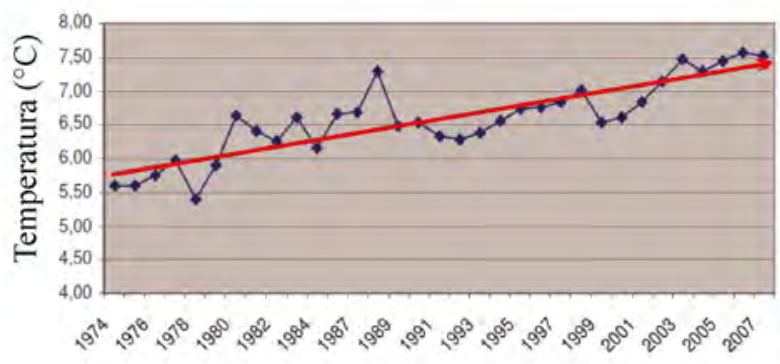

Años

\section{C.}

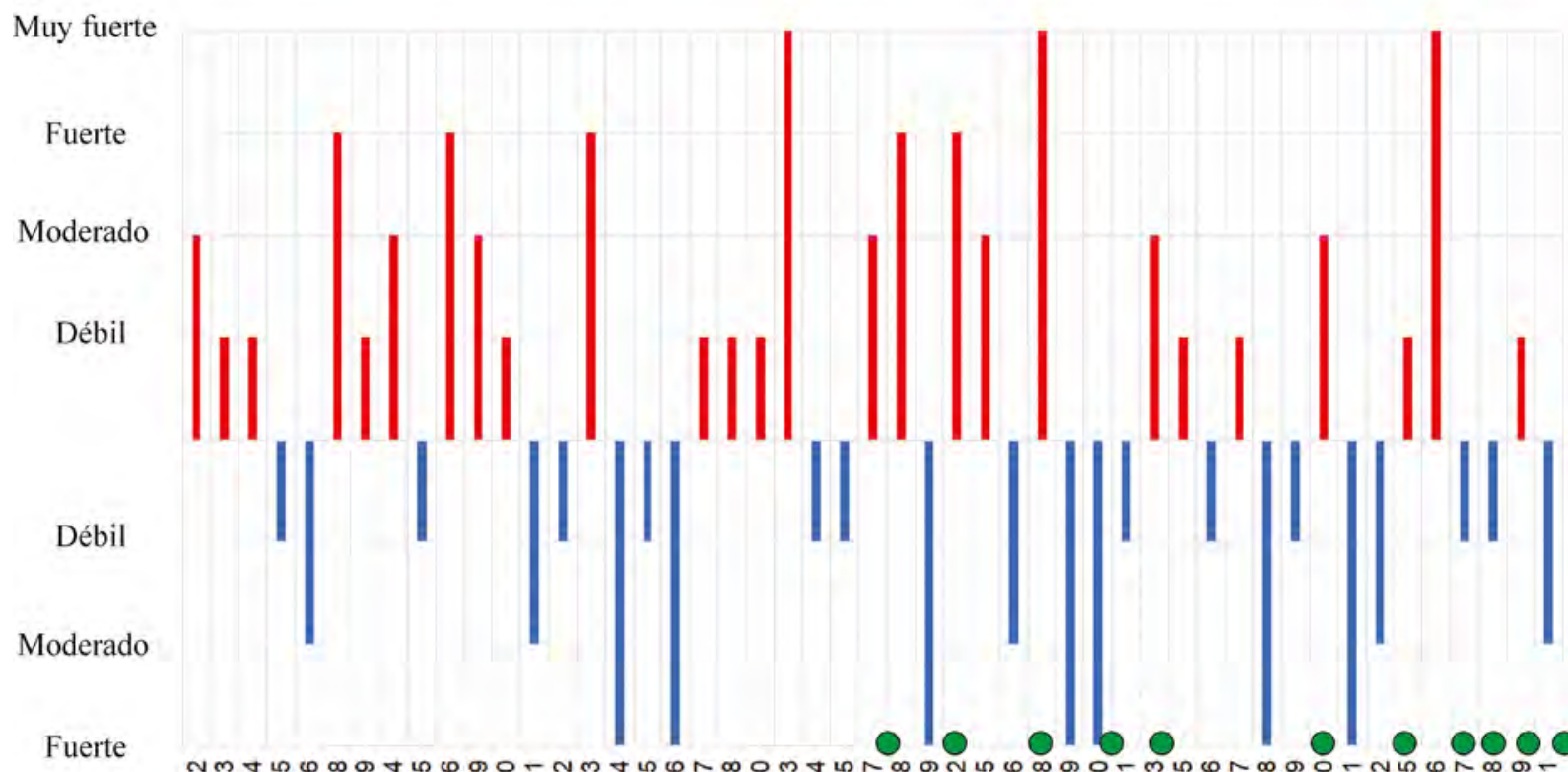

Fuerte

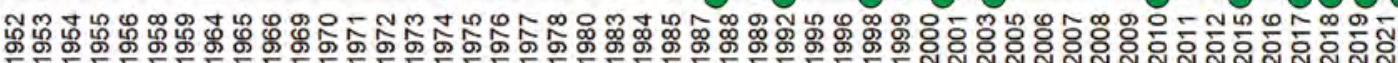

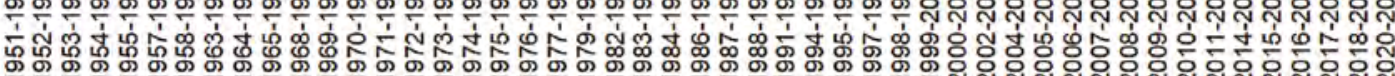

Fenómeno de El Niño

Fenómeno de La Niña

Imagen analizada

Figura 14. Factores meteorológicos. A. Valores de precipitación media anual, estación Sierra Nevada El Cocuy (IDEAM, 2010b). B. Valores de temperatura media anual, estación Sierra Nevada El Cocuy (IDEAM, 2010b). C. Dinámica del ENSO. Los eventos del ENSO se clasifican en débiles (con una anomalía de Sea Surface Temperature (SST) de 0,5 a 0,9), moderados (1,0 a $1,4)$, fuertes $(1,5$ a 1,9$)$ y muy fuertes $(\geq 2,0)$, por encima de la anomalía de $0,5^{\circ}$ para eventos cálidos (El Niño) y por debajo de $-0,5^{\circ}$ para eventos fríos (La Niña). Modificado de Null (2021). 


\section{Conclusiones}

La metodología usada en este trabajo permitió identificar clases específicas (área glaciar, suelo-roca, vegetación y agua) para el área de estudio mediante la interpretación visual de imágenes. A partir de las 11 escenas analizadas (Landsat y Sentinel-2) y datos previos de otros autores, es evidente el retroceso glaciar de la SRC desde finales del siglo XX, con una pérdida aproximada de 1099,59 ha, correspondiente al $37,92 \%$ de cobertura en los últimos 34 años. La cobertura glaciar exhibe los valores más altos de exactitud ( $>95 \%$ ), indicando la confiabilidad de los resultados obtenidos durante la clasificación.

Según los resultados, la rápida tasa de pérdida glaciar en la SRC llevaría a la extinción del glaciar en el año 2048. Dicha pérdida se producirá de manera más rápida en la vertiente occidental, donde las pendientes son menos pronunciadas, debido a esto, posiblemente se pueden generar inundaciones por desborde violento de lago glaciar (Glacier lake outburst flood-GLOF) que es un tipo de inundación súbita que se produce cuando los elementos de contención -hielo glaciar o una morrena terminal- de un lago fallan (Carey, 2014). Este tipo de fenómeno puede representar un riesgo para las poblaciones y las infraestructuras localizadas aguas abajo afectando las zonas aledañas a la SRC.

La tasa de retroceso puede verse afectada por el incremento de los valores medios de temperatura anual y disminución en los valores de precipitación registrados durante los últimos años. Esto como consecuencia del efecto del cambio climático y el fenómeno de El Niño en la extensión y dinámica de los glaciares tropicales. El estudio de los glaciares tropicales es de suma importancia para entender la disponibilidad del recurso hídrico en las altas montañas de Colombia. Además, el monitoreo del área glaciar de la SRC permite el desarrollo de medidas de mitigación frente al deshielo, el cual compromete el acceso al agua por parte de los municipios aledaños.

\section{Agradecimientos}

Agradecemos al Servicio Geológico Americano (USGS) y a la Iniciativa Internacional sobre Clima y Bosques de Noruega (NICFI) por el acceso a las imágenes usadas en este estudio, y al IDEAM por el suministro de los datos meteorológicos. Además, agradecemos al Programa de Pós-graduação em Geologia e Geoquímica-UFPA, Brasil por el acceso al laboratorio de sensores remotos y uso del software especializado.

\section{Referencias}

Ancizar, M. (1955). La Sierra Nevada de Güicán, Cocuy o Chita. Boletín de la Sociedad Geográfica de Colombia, 13(45-46).

Andreassen, L.; Moholdt, G.; Kääb, A.; Messerli, A.; Nagy, T.; Havstad, S. (2021). Monitoring glaciers in mainland Norway and Svalbard using Sentinel. Norwegian Water Resources and Energy Directorate (NVE).

Anderson, E.; Marengo, J.; Villalba, R.; Halloy S.; Young, B.; Cordero, D.; Gast, F.; Jaimes, E.; Ruiz, D. (2011). Consequences of climate change for ecosystems and ecosystem services in the Tropical Andes. In: S. Herzog, R. Martinez, P. Jørgensen, $\mathrm{H}$. Tiessen (eds.). Climate change and biodiversity in the Tropical Andes (pp. 1-19). Inter-American Institute for Global Change Research.

Bautista, W.; Correa, H. (2018). Dinámica de cambio para el glaciar nevado el Cocuy en Colombia. Propuesta metodológica que evalúa el comportamiento y evolución a partir de teledetección y modelación de variables climatológicas para los periodos (1987 - 1997 - 2009 - 2015). Tesis, Universidad Distrital Francisco José de Caldas, Bogotá, Colombia.

Boretti, A. (2020). The European colonization of the Americas as an explanation of the Little Ice Age. Journal of Archaeological Science: Reports, 29. https://doi.org/10.1016/j.jasrep.2019.102132

Carey, M. (2014). Glaciares, cambio climático y desastres naturales. Ciencia y sociedad en el Perú, Institut Français d'études Andines - IFEA, Instituto de Estudios Peruanos.

Ceballos, J.; Euscategui, C.; Ramírez, J.; Cañon, M.; Huggel, C.; Haeberli, W.; Machguth, H. (2006). Fast shrinkage of tropical glaciers in Colombia. Annals of Glaciology, 43, 194-201. https://doi. org/10.3189/172756406781812429

Ceballos, J.; Tobón, E.; Arias, M.; Carvajal, J.; López, O.; Buitrago, V.; Valderrama, J.; Ramírez, J. (2010). Glaciares Santa Isabel y el Cocuy (Colombia): Seguimiento a su dinámica durante el período 2006-2008. En: C. López-Arenas, J. Ramírez-Cadena (eds.). Glaciares, nieves y hielos 
de América Latina: Cambio climático y amenazas (pp. 91-114). INGEOMINAS.

Congalton, R.; Green, K. (2008). Assessing the accuracy of remotely sensed data: Principles and Practices. 2nd ed. CRC Press Taylor \& Francis Group.

Cooper,M.;Addison,F.;Alvarez, R.; Coral,M.; Graham, R.; Hayward, A.; Howe, S.; Martinez, J.; Naar, J.; Peñas, R.; Pulham, A.;Taborda, A. (1995). Basin development and tectonic history of the Llanos Basin, Eastern Cordillera, and Middle Magdalena Valley, Colombia. AAPG Bulletin, 79(10), 14211443. https://doi.org/10.1306/7834D9F4-172111D7-8645000102C1865D

Domine, F.; Salvatori, R.; Legagneux, L.; Salzano, R.; Fily, M.; Casacchia, R. (2006). Correlation between the specific surface area and the short wave infrared (SWIR) reflectance of snow. Cold Regions Science and Technology, 46(1), 60-68. https://doi.org/10.1016/j.coldregions.2006.06.002

Dong, C. (2018). Remote sensing, hydrological modeling and in situ observations in snow cover research: a review. Journal of Hydrology, 561, 573-583. https://doi.org/10.1016/j. jhydrol.2018.04.027

Dozier, J. (1989). Spectral signature of alpine snow cover from the Landsat thematic mapper. Remote Sensing of Environment, 28, 9-22. https://doi. org/10.1016/0034-4257(89)90101-6

Ducrot, D.; Masse, A.; Marais-Sicre, C.; Dejoux, J.; Baup, F. (2010). Multisensor and multitemporal image fusion methods to improve remote sensing image classification. Centre d'Etudes Spatiales de La Biosphère. Valencia, Spain. https://doi. org/10.13140/2.1.2607.0084

Etayo, F.; Renzoni, G.; Barrero, D. (1969). Contornos sucesivos del mar Cretáceo en Colombia. I Congreso Colombiano de Geología, Bogotá.

Euscategui, C. (2002). Incidencia de las variaciones del brillo solar en la dinámica glaciar del volcán nevado Santa Isabel (Cordillera Central, Colombia). Bogotá, Meteorología Colombiana.

Fabre, A. (1981). Geología regional de la Sierra Nevada del Cocuy de la Plancha 137 El Cocuy. Bogotá. INGEOMINAS.
Fabre, A.; Osorio, M.; Vargas, R. (1984). Geología de la Plancha 153 Chita. Bogotá. INGEOMINAS.

Fabre, A.; Osorio, M.; Vargas, R. (1985). Geología de la Plancha 137 Cocuy. Bogotá. INGEOMINAS.

Feo, O.; Solano, E.; Beingolea, L.; Aparicio, M.; Villagra, M.; Prieto, M.; García, J.; Jiménez, P.; Betancourt, O.; Aguilar, M.; Beckmann, J.; Gastañaga, M.; Llanos-Cuentas, A.; Osorio, A.; Silveti, R. (2009). Cambio climático y salud en la región andina. Revista Peruana de Medicina Experimental y Salud Pública, 26(1), 83-92.

Florez, A. (1991). La Sierra Nevada del Cocuy, Chita o Güicán. EPG-Geografia, 1(2), 7-18.

Foody, G. (2002). Status of land cover classification accuracy assessment. Remote Sensing of Environment, 80(1), 185-201. https://doi. org/10.1016/S0034-4257(01)00295-4

García, M.; Piñeros, A.; Bernal, F.; Ardila, E. (2012). Variabilidad climática, cambio climático y el recurso hídrico en Colombia. Revista de Ingeniería, 36, 60-64.

Google Earth. (2020). Google Earth. https://earth. google.com/web

Guillen, J.; Santiago, J.; Soria, M. (2004). Estudio multitemporal del retroceso glaciar a través de imágenes de sensores remotos y SIG en la Sierra Nevada del Cocuy, Cordillera Oriental de Colombia para el periodo 1960-2003. Tesis, Universidad Distrital Francisco José de CaldasIGAC, Bogotá, Colombia.

Guiot, J.; de Vernal, A. (2011). Is spatial autocorrelation introducing biases in the apparent accuracy of paleoclimatic reconstructions? Quaternary Science Reviews, 30(15-16), 1965-1972. https:// doi.org/10.1016/j.quascirev.2011.04.022

Gutzler D.; Preston J. (1997). Evidence for a relationship between spring snow cover in North America and summer rainfall in New Mexico. Geophysical Research Letters, 24(17), 22072210. https://doi.org/10.1029/97GL02099

Härer, S.; Bernhardt, M.; Siebers, M.; Schulz, K. (2018). On the need for a time- and locationdependent estimation of the NDSI threshold value 
for reducing existing uncertainties in snow cover maps at different scales. The Cryosphere, 12(5), 1629-1642. https://doi.org/10.5194/tc-12-16292018

Herrera, G.; Ruiz, J. (2008). Retroceso glaciar en la Sierra Nevada del Cocuy, Boyacá - Colombia, 1986-2007. Perspectiva Geográfica, 13, 27-36. https://doi.org/10.19053/01233769.1710

Hoyos-Patiño, F. (1998). Glaciers of Colombia. In: R. Williams, J. Ferrigno (eds.). Satellite image atlas of glaciers of the world - South America (pp. 11-30). United States Geological Survey Professional Paper.

IDEAM. (2001). Los glaciares colombianos, expresión del cambio climático global.

IDEAM. (2007). Modelo institucional del IDEAM sobre el efecto climático de los fenómenos El Niño y La Niña en Colombia. Bogotá, Instituto de Hidrología, Meteorología y Estudios Ambientales.

IDEAM. (2010a). Atlas climatológico de Colombia. http://atlas.ideam.gov.co/ visorAtlasClimatologico.html

IDEAM. (2010b). Informe de actividades glaciológicas: Sierra Nevada de El Cocuy y volcán nevado Santa Isabel Colombia. Bogotá, Instituto de Hidrología, Meteorología y Estudios Ambientales.

IDEAM. (2012). Glaciares de Colombia, más que montañas con hielo.

IDEAM. (2019). Sierra Nevada El Cocuy o Güicán. http://www.ideam.gov.co/web/ecosistemas/ sierra-nevada-cocuy-Güicán

Kaser, G.; Georges, C. (1999). On the mass balance of low latitude glaciers with particular consideration of the Peruvian Cordillera Blanca. Geografiska Annaler: Series A, Physical Geography, 81(4), 643-651. https://doi.org/10.1111/14680459.00092

Knight, P. (1999). Glaciers. Stanley Thornes (Publishers) Ltd.

König, M; Winther, J.; Isaksson, E. (2001). Measuring snow and glacier ice properties from satellite. Reviews of Geophysics, 39(1), 1-27. https://doi. org/10.1029/1999RG000076
Li, J.; Roy, A. (2017). A global analysis of Sentinel-2A, Sentinel-2B and Landsat- 8 data revisit intervals and implications for terrestrial monitoring. Remote Sensing, 9(9). https://doi.org/10.3390/ rs9090902

López-Moreno, J.; Ceballos, J.; Rojas-Heredia, F.; Zabalza-Martinez, F.; Vidaller, I.; Revuelto, J.; Alonso-González, E.; Morán-Tejada, E.; García-Ruiz, J. (2020). Topographic control of glacier changes since the end of the Little Ice Age in the Sierra Nevada de Santa Marta mountains, Colombia. Journal of South American Earth Sciences, 104. https://doi.org/10.1016/j. jsames.2020.102803

Mark, B. (2008). Tracing tropical Andean glaciers over space and time: some lessons and transdisciplinary implications. Global and Planetary Change, 60(1-2), 101-114. https://doi.org/10.1016/j. gloplacha.2006.07.032

Matthews, J.; Briffa, K. (2005). The 'Little Ice Age': re-evaluation of an evolving concept. Geografiska Annaler: Series A, Physical Geography, 87(1), 17-36. https://doi.org/10.1111/j.04353676.2005.00242.x

Metsämäki, S.; Pulliainen, J.; Salminen, M.; Luojus, K.; Wiesmann, A.; Solberg, R.; Böttcher, Kristin.; Hiltunen, M.; Ripper, E. (2015). Introduction to GlobSnow snow extent products with considerations for accuracy assessment. Remote Sensing of Environment, 156, 96-108. https://doi. org/10.1016/j.rse.2014.09.018

Morris, J.; Poole, A.; Klein, A. (2006). Retreat of tropical glaciers in Colombia and Venezuela from 1984 to 2004 as measured from ASTER and Landsat images. 63rd Eastern Snow Conference. Newark, Delaware.

Muñoz, F.; Ariano, R.; Buitrago, V.; Reyes, M.; Carvajal, J.; Valderrama, J.; Valderrama, R.; Gutierrez, R.; Blanco, M.; Suescun, J.; Navarrete, S.; Trujillo, M.; Aguilar, C.; Ospina, M.; Peñalosa, C.; Uribe, D.; Martinez, J. (2005). Plan de manejo 2005-2009 Parque Nacional Natural El Cocuy. El Cocuy, Sácama, Tame: Parques Nacionales Naturales de Colombia.

Nolin, A. (2010). Recent advances in remote sensing of seasonal snow. Journal of 
Glaciology, 56(200), 1141-1150. https://doi. org/10.3189/002214311796406077

Null, J. (2021). El Niño and La Niña years and intensities. Golden Gate Weather Services. https:// ggweather.com/enso/oni.htm

Painter, T.; Roberts, D.; Green, R.; Dozier, J. (1998). The effect of grain size on spectral mixture analysis of snow-covered area from AVIRIS data. Remote Sensing of Environment, 65(3), 320-332. https://doi.org/10.1016/S0034-4257(98)00041-8

Peña, J. (2015). Análisis multitemporal del retroceso glaciar de la Sierra Nevada del Cocuy ubicada en los departamentos de Boyacá y Arauca entre los años 1992, 2003 y 2014. Tesis, Universidad Militar Nueva Granada, Bogotá, Colombia.

Planet (2020). Planet. https://www.planet.com

Pontius, R.; Millones, M. (2011). Death to Kappa: birth of quantity disagreement and allocation disagreement for accuracy assessment. International Journal of Remote Sensing, 32(15), 4407-4429. https://doi.org/10.1080/01431161.20 11.552923

Poveda, G.; Waylen, P.; Pulwarty, R. (2006). Annual and inter-annual variability of the present climate in northern South America and southern Mesoamerica. Palaeogeography, Palaeoclimatology, Palaeoecology, 234(1), 3-27. https://doi.org/10.1016/j.palaeo.2005.10.031

Quintero, J. (2018). Cálculo de retroceso para los glaciares colombianos por medio de imágenes satelitales Sentinel 2 y MDT para el 2016 - 2017. Tesis, Universidad de Manizales, Manizales, Colombia.

Rabatel, A.; Jomelli, V.; Naveau, P.; Francou, B.; Grancher, D. (2005). Dating of Little Ice Age glacier fluctuations in the tropical Andes: Charquini glaciers, Bolivia, $16^{\circ} \mathrm{S}$. Comptes Rendus Geoscience, 337(15), 1311-1322. https:// doi.org/10.1016/j.crte.2005.07.009

Rabatel, A.; Francou, B.; Soruco, A.; Gomez, J.; Cáceres, B.; Ceballos, J.; Basantes, R.; Vuille, M.; Sicart, J.; Huggel, C.; Scheel, M.; Lejeune, Y.; Arnaud, Y.; Collet, M.; Condom, T.; Consoli, G.; Favier, V.; Jomelli, V.; Galarraga, R.; Ginot,
P.; Maisincho, L.; Mendoza, J.; Ménégoz, M.; Ramirez, E.; Ribstein, P.; Suarez, W.; Villacis, M.; Wagnon, P. (2013). Current state of glaciers in the tropical Andes: a multi-century perspective on glacier evolution and climate change. The Cryosphere, 7(1), 81-102. https://doi.org/10.5194/ tc-7-81-2013

Rapp, D. (2014). Assessing climate change: Temperatures, solar radiation and heat balance. Springer Cham Heidelberg. https://doi. org/10.1007/978-3-319-00455-6

Rekowsky, I.; Bremer, U.; Veettil, B. (2018). Variações de área das geleiras da Colômbia e da Venezuela entre 1985 e 2015 com dados de sensoriamento remoto. Geociências, 37(3), 569-581. https://doi. org/10.5016/geociencias.v37i3.11946

Rodrigues, S.; Souza-Filho, P. (2011). Use of multisensor data to identify and map tropical coastal wetlands in the Amazon of Northern Brazil. Wetlands, 31(1), 11-23. https://doi.org/10.1007/ s13157-010-0135-6

Rodríguez, J. (2015). Análisis de la distribución espacial de la precipitación máxima en 24 horas en el Parque Nacional Natural El Cocuy. Tesis, Universidad Militar Nueva Granada, Bogotá, Colombia.

Rowan, A. (2017). The 'Little Ice Age' in the Himalaya: A review of glacier advance driven by Northern Hemisphere temperature change. The Holocene, 27(2), 292-308. https://doi. org/10.1177/0959683616658530

Santos, D.; Souza-Filho, P.; Nascimento, W.; Cardoso, G.; Santos, J. (2020). Land cover change, landscape degradation, and restoration along a railway line in the Amazon biome, Brazil. Land Degradation \& Development, 31(15), 2033-2046. https://doi.org/10.1002/ldr.3514

Silva, G. (2010). Tipos y subtipos climáticos de Venezuela. Tesis, Universidad de los Andes, Merida, Venezuela.

Singh, D.; Thakur, P.; Naithani, B.; Kaushik, S. (2020). Quantifying the sensitivity of band ratio methods for clean glacier ice mapping. Spatial Information Research, 29(3), 281-295. https:// doi.org/10.1007/s41324-020-00352-8 
Sood, V.; Gusain, H.; Gupta, S.; Taloor, A.; Singh, S. (2021). Detection of snow/ice cover changes using subpixel-based change detection approach over Chhota-Shigri glacier, Western Himalaya, India. Quaternary International, 575-576, 204212. https://doi.org/10.1016/j.quaint.2020.05.016

Souza-Filho, P.; Nascimento, W.; Santos, D.; Weber, E.; Silva, R.; Siqueira, J. (2018). A GEOBIA approach for multitemporal land-cover and landuse change analysis in a tropical watershed in the Southeastern Amazon. Remote Sensing, 10(11). https://doi.org/10.3390/rs10111683

Valdez-Cepeda, R.; Hernández-Ramírez, D.; Mendoza, B.; Valdés-Galicia, J.; Maravilla, D. (2003). Fractality of monthly extreme minimum temperature. Fractals, 11(2), 137-144. https://doi. org/10.1142/S0218348X0300163X

Varade, D.; Maurya, A.; Sure, A.; Dikshit, O. (2017). Supervised classification of snow cover using hyperspectral imagery. International Conference on Emerging Trends in Computing and Communication Technologies, Dehradun, India. https://doi.org/10.1109/ICETCCT.2017.8280302

Veettil, B. (2017). Identificação da influência de El Niño - oscilação sul e oscilação decenal do Pacífico sobre as geleiras andinas tropicais usando sensoriamento remoto e parâmetros climáticos. Tese, Universidade Federal do Rio Grande do Sul, Porto Alegre, Brasil.

Veettil, B.; Kamp, U. (2019). Global disappearance of tropical mountain glaciers: observations, causes, and challenges. Geosciences, 9(5), 196. https:// doi.org/10.3390/geosciences9050196

Waliser, D.; Jiang, X. (2015). Tropical meteorology and climate, Intertropical Convergence Zone. In: G. North, J. Pyle, F. Zhang (eds.). Encyclopedia of atmospheric sciences (pp. 121-131). 2nd ed. Academic Press. https://doi.org/10.1016/B978-012-382225-3.00417-5

Wang, X.; Wang, J.; Jiang, Z.; Li, H.; Hao, X. (2015). An effective method for snow-cover mapping of dense coniferous forests in the Upper Heihe River Basin using Landsat operational land imager data. Remote Sensing, 7(12), 17246-17257. https://doi. org/10.3390/rs71215882

Wang, Y.; Huang, X.; Liang, H.; Sun, Y.; Feng, Q.; Liang, T. (2018). Tracking snow variations in the Northern Hemisphere using multi-source remote sensing data (2000-2015). Remote Sensing, 10(1). https://doi.org/10.3390/rs10010136

Wulder, M.; Loveland, T.; Roy, D.; Crawford, C.; Masek, J.; Woodcock, C.; Allen, R.; Anderson, M.; Belward, A.; Cohen, W.; Dwyer, J.; Erb, A.; Gao, F.; Griffiths, P.; Helder, D.; Hermosilla, T.; Hipple, J.; Hostert, P.; Hughes, M.; Huntington, J.; Johnson, D.; Kennedy, R.; Kilic, A.; Li, Z.; Lymburner, L.; McCorkel, J.; Pahlevan, N.; Scambos, T.; Schaaf, C.; Schott, J.; Sheng, Y.; Storey, J.; Vermote, E.; Vogelmann, J.; White, J.; Wynne, R.; Zhu, Z. (2019). Current status of Landsat program, science, and applications. Remote Sensing Environment, 225, 127-147. https://doi.org/10.1016/j.rse.2019.02.015

Xiao, X.; Shen, Z.; Qin, X. (2001). Assessing the potential of vegetation sensor data for mapping snow and ice cover: A Normalized Difference Snow and Ice Index. International Journal of Remote Sensing, 22(13), 2479-2487. https://doi. org/10.1080/01431160119766

Yan, Y. (2005). Intertropical Convergence Zone (ITCZ). In: J. Oliver (ed.). Encyclopedia of world climatology (pp. 429-432). Springer, Dordrecht. https://doi.org/10.1007/1-4020-3266-8_110

Zhang, M.; Zhao, H.; Chen, F.; Zeng, J. (2020). Evaluation of effective spectral features for glacial lake mapping by using Landsat-8 OLI imagery. Journal of Mountain Science, 17(11), 2707-2723. https://doi.org/10.1007/s11629-020-6255-4

Fecha de recibido: 21 de agosto de 2021 Fecha de aprobado: 30 de noviembre de 2021 